\title{
Evaluation of Corrosion Inhibition Efficiency of Aluminum Alloy 2024 by Diaminostilbene and Azobenzene Schiff Bases in $1 \mathrm{M}$ Hydrochloric Acid
}

\author{
Shobha Bhaskara, ${ }^{1}$ Sanaulla Pathapalya Fakrudeen $\mathbb{D}^{1},{ }^{2}$ Tegene Desalegn, ${ }^{3}$ \\ H. C. Ananda Murthy $\left(0^{3}{ }^{3}\right.$ and V. Bheemaraju ${ }^{1}$ \\ ${ }^{1}$ Department of Chemistry, Dr Ambedkar Institute of Technology, Bangalore 560056, India \\ ${ }^{2}$ Department of Chemistry, HKBK College of Engineering, Bangalore, 560045 Karnataka, India \\ ${ }^{3}$ Department of Applied Chemistry, Adama Science and Technology University, Adama, P.O. Box 1888, Ethiopia \\ Correspondence should be addressed to Sanaulla Pathapalya Fakrudeen; sanahkbk@gmail.com
}

Received 26 May 2021; Revised 30 August 2021; Accepted 14 September 2021; Published 21 October 2021

Academic Editor: Michael J. Schütze

Copyright (c) 2021 Shobha Bhaskara et al. This is an open access article distributed under the Creative Commons Attribution License, which permits unrestricted use, distribution, and reproduction in any medium, provided the original work is properly cited.

The Schiff base compounds N,N'-bis(salicylidine)-4,4'-diaminostilbene(SDS) and N, $\mathrm{N}^{\prime}$-bis(salicylidine)-4,4'-diamino azobenzene(SDA) were synthesized, and their molecular structure was determined by FT-IR and 1H NMR. The corrosion inhibitions of Schiff base compounds on aluminum alloy 2024 in $1 \mathrm{M}$ hydrochloric acid were evaluated by potentiodynamic polarization, impedance techniques, weight loss method, and scanning electron microscopic technique. The potentiodynamic polarization (PDP) studies revealed that SDS and SDA compounds acted predominantly as cathodic inhibitors. The electrochemical impedance spectroscopic (EIS) parameters confirmed the adsorption of SDS and SDA molecules over the surface of aluminum alloy 2024 alloy by forming an inhibitive layer. The weight loss studies showed that the inhibition efficiency of these compounds increases directly with concentration and decreases with an increase in solution temperature and immersion time. The thermodynamic parameters were calculated to investigate the mechanism of corrosion inhibition. The SDA was found to be more effective than SDS and followed the Langmuir adsorption isotherm model. The scanning electron microscopy (SEM) results revealed that the deterioration of the alloy surface is minimal in the presence of an inhibitor. Both Schiff base molecules exhibited superior corrosion inhibition for aluminum alloy 2024 alloy in $\mathrm{HCl}$ medium.

\section{Introduction}

Aluminum alloy 2024 is a high strength alloy that finds its utility in products that require a high strength-to-density ratio and good resistance to fatigue. Because of its very good durability and tolerance towards damage, toughness, fractures, fatigue, crack propagation, and low cost to manufacture, it is often being used in automotive, transportation, and aerospace industries $[1,2]$. Its high strength is due to the presence of copper, magnesium, and manganese. The higher percentage (3.8-4.9\%) of copper in 2024 aluminum alloy greatly reduces its resistance to corrosion [3]. AA2024 alloy is very much susceptible to localized corrosive attack since the intermetallic compounds at the boundary get segregated. The localized pitting corrosion starts where the most predominant intermetallic inclusions exist. $\mathrm{Al} 2 \mathrm{MgCu}$ is one such inclusion and reveals cathodic potential concerning the alloy matrix. Magnesium and aluminum get chemically and electrochemically dissolved from $\mathrm{Al} 2 \mathrm{MgCu}$ particles at the beginning of corrosion which leads to dealloying enriching them with copper. The intermetallic precipitates become active anodes and cathodes, resulting in deep dealloying of the matrix [4].

The corrosion inhibition by triazole and thiazole derivatives against aluminum-based copper-containing alloys was studied earlier [5, 6]. 2-Mercaptobenzothiazole, 8-hydroxyquinoline, and benzotriazole were used as corrosion inhibitors on AA 2024-T3 [7]. 2-(4-(Diethylamino)-2- 
hydroxybenzyledene) hydrazinecarboamide was also applied as corrosion inhibitor for AA2024-T3 alloy in acid solution [8]. Organic inhibitors were also studied as inhibitors of corrosion for aluminum and its alloys in both acidic and basic solutions [9]. Thymus algeriensis extract was experimented as corrosion inhibitor for AA2024 alloy in an acidic medium [10]. Many Schiff bases were also applied as corrosion inhibitors for aluminum alloys in acidic solution [11-14]. In general, various organic and inorganic inhibitors were utilized by past researchers, as corrosion inhibitors for AA2024 alloy in acidic and neutral chloride solutions [15-27], but no significant study has been conducted on the evaluation of corrosion inhibition of AA2024 alloys in acidic media by organic inhibitors.

The AA2024 alloy was found to exhibit a high degree of susceptibility to severe corrosion in acid media. The electrochemical etching of aluminum and its alloys usually involves the application of $\mathrm{HCl}$. As the dissolution rate of AA2024 alloy in $\mathrm{HCl}$ solution is very high, it is necessary to avoid the dissolution of alloy by adding inhibitors as additives in the etching medium. Organic inhibitors have the ability to control the corrosion in metal alloys by forming an insoluble layer on the surface of the alloys. In general, organic inhibitors get adsorbed on metal alloy surfaces by chemisorption by forming coordination bonds with the atoms or ions by physisorption through electrostatic interaction between the alloy and inhibitors. Electronegative groups found in inhibitor molecules such as $\mathrm{S}, \mathrm{P}, \mathrm{O}$, and $\mathrm{N}$ atoms assist in strong bond formation on the metal surface [28].

However, investigation of inhibitive action of $\mathrm{N}, \mathrm{N}^{\prime}$ -bis(salicylidine)-4, $4^{\prime}$-diaminostilbene (SDS) and $\mathrm{N}, \mathrm{N}^{\prime}$ -bis(salicylidine)-4,4-diamino azobenzene(SDA) in acid medium on the corrosion behavior of AA2024 alloy has not yet been explored. Thus, we present this work targeting the evaluation of corrosion inhibitive effect of N,N ${ }^{\prime}$-bis(salicylidine)- $4,4^{\prime}$-diaminostilbene (SDS) and N, $\mathrm{N}^{\prime}$-bis(salicylidine)-4, $4^{\prime}$-diaminoazobenzene (SDA) on AA2024 alloy in presence of $1 \mathrm{M} \mathrm{HCl}$ using PDP, EIS, and weight loss methods.

\section{Materials and Methods}

2.1. Test Specimens. Aluminum alloy 2024 ingots were procured from M/s. Fenfee Metals, Bengaluru, India. The aluminum alloy 2024 ingots were melted and moulded into $26 \mathrm{~mm}$ diameter $\times 170 \mathrm{~mm}$ length cylindrical rods using the gravity die casting method at Metallurgical Lab, Chemistry Department, HKBK College of Engineering, Bengaluru, India. The elemental composition of alloy was analyzed using Optical Emission Spectrometry (as per IS: 7658) at CMTI Lab, Bengaluru. The composition was found to be within the range of ASTM specifications as shown in Table 1.

The test specimen for weight loss studies and the cylindrical rods were cut into circular discs using the abrasive cutting wheel. Each circular disc measuring a height of $2 \mathrm{~mm}$ and a diameter of $24 \mathrm{~mm}$ and having a $2 \mathrm{~mm}$ mounting hole at the center was prepared. The test specimens for electrochemical studies were prepared by moulding the
TABLe 1: The elemental composition of AA 2024 alloy.

\begin{tabular}{lc}
\hline Element & $\mathrm{Wt} \%$ \\
\hline $\mathrm{Al}$ & $90.7-94.7$ \\
$\mathrm{Cu}$ & $3.8-4.9$ \\
$\mathrm{Mg}$ & $1.2-1.8$ \\
$\mathrm{Si}$ & Maximum 0.5 \\
$\mathrm{Fe}$ & Maximum 0.5 \\
$\mathrm{Mn}$ & $0.3-0.9$ \\
$\mathrm{Ti}$ & Maximum 0.15 \\
$\mathrm{Cr}$ & Maximum 0.1 \\
$\mathrm{Zn}$ & Maximum 0.25 \\
Others & Maximum 0.15 \\
\hline
\end{tabular}

cylindrical rods of $20 \mathrm{~mm}$ length in cold setting acrylic resin. In such a way, leaving the alloy surface of $1.0 \mathrm{~cm}^{2}$ area is exposed on one end, and another end is connected to copper wire for electrical contact. Before each experimental trial, the electrodes were polished with emery papers of various grades ranging from 6 to 12 hundred for a smooth surface. The specimens were washed with double distilled water and acetone for degreasing and finally drying at $353 \pm 1 \mathrm{~K}$ for over half-hour in a thermostat electric oven. The alloy specimens were placed in a moisture-free desiccator.

2.2. Test Solution-Corrosion Medium. The corrosive medium $1 \mathrm{M} \mathrm{HCl}$ was prepared by diluting analytical grade $37 \%$ acid (SDFCL) in double-distilled water. The stock solution of $1000 \mathrm{ppm}$ Schiff bases was prepared in $1 \mathrm{M} \mathrm{HCl}$, and $25,50,75$, and $100 \mathrm{ppm}$ solutions were prepared by further dilution in $1 \mathrm{M} \mathrm{HCl}$.

2.3. Synthesis and Characterization of Schiff Base Inhibitors. The Schiff base compounds under investigation were synthesized in accordance with the method used by Hossein Naeimi and Arash Heidarnezhad [29]. The diaminostilbene and azobenzene Schiff bases were prepared by condensing the corresponding aromatic aldehydes with $4,4^{\prime}$-diaminostilbene and $4,4^{\prime}$-diaminoazobenzene as shown in Scheme 1. The structural elucidation of the synthesized compound was confirmed by FT-IR and ${ }^{1} \mathrm{H}$ NMR spectral studies along with its melting points (Table 2).

\section{Experimental Methods}

3.1. Weight Loss Measurement. The weight loss experiments were performed as per ASTM [30] under different parameters like duration of a specimen immersed, the solution temperature, and the concentration of inhibitor. Before each experiment, the following cleaning actions were performed:

(i) Electrodes were abraded using emery papers (grades 600,800 , and 1200)

(ii) Electrodes were washed with double-distilled water and degreased using acetone 


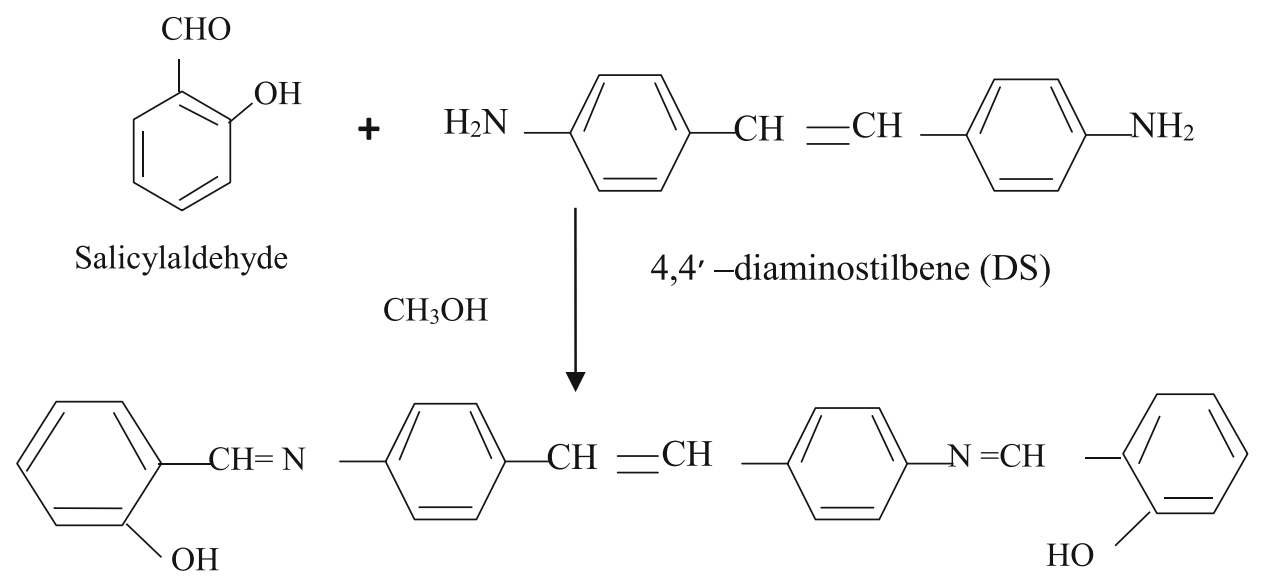

N,N'-bis (salicylidine)-4,4' -diaminostilbene(SDS)<smiles>O=Cc1ccccc1Cl</smiles>

Salicylaldehyde<smiles>Nc1ccc(N=C=Nc2ccc(N)cc2)cc1</smiles><smiles>O=Cc1ccccc1O</smiles>

4,4' - diaminoazobenzene (DA)

\section{$\mathrm{CH}_{3} \mathrm{OH}$}

4, - diaminoazobenzene (DA)

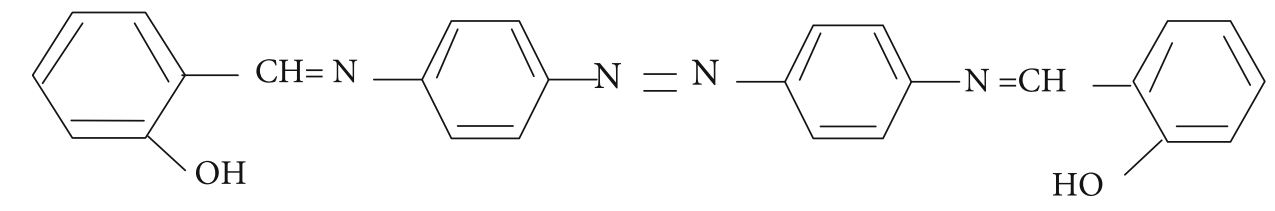

$\mathrm{N}, \mathrm{N}^{\prime}$-bis (salicylidine) -4,4' -diaminoazobenzene(SDA)

Scheme 1: Synthesis of diaminostilbene and azobenzene Schiff bases.

TABle 2: ((FT-IR), ${ }^{1} \mathrm{H}$ NMR), molecular formula, and melting point data of SDS and SDA.

\begin{tabular}{|c|c|c|}
\hline No. & Diamines & IR and ${ }^{1} \mathrm{H}$ NMR data \\
\hline (1) & $\begin{array}{l}\mathrm{N}, \mathrm{N}^{\prime} \text {-bis(Salicylidine) }-4,4^{\prime} \\
\text {-diaminostilbene (SDS) } \\
\text { Molecular formula: } \mathrm{C}_{28} \mathrm{H}_{22} \mathrm{~N}_{2} \mathrm{O}_{2} \\
\text { Molecular mass: } 418.28 \mathrm{~g} / \mathrm{Mol} \\
\text { Melting point: } 240-244^{\circ} \mathrm{C}\end{array}$ & $\begin{array}{c}\mathrm{IR} / v(\mathrm{KBr}) \mathrm{cm}^{-1}: 3320-3500,2940-2990,1605,1150,1130 \\
\left.{ }^{1} \mathrm{H} \text { NMR (DMSO-d6, } 500 \mathrm{MHz}\right) \delta(\mathrm{ppm}): 13(\mathrm{~s}, 2 \mathrm{H}), 8.5(\mathrm{~s}, 2 \mathrm{H}), 7-7.9(\mathrm{~m}, 16 \mathrm{H}) \text {, and } 6.8(\mathrm{~d}, \\
\text { 2H). MS (EI, m/z): } 418(\mathrm{M}+, 7) \text { and } 392(11)\end{array}$ \\
\hline (2) & $\begin{array}{l}\mathrm{N}, \mathrm{N}^{\prime} \text {-bis(Salicylidine) }-4,4^{\prime} \\
\text {-diaminoazobenzene (SDA) } \\
\text { Molecular formula: } \mathrm{C}_{26} \mathrm{H}_{20} \mathrm{~N}_{4} \mathrm{O}_{2} \\
\text { Molecular mass: } 420.26 \mathrm{~g} / \mathrm{Mol} \\
\text { Melting point: }>300^{\circ} \mathrm{C}\end{array}$ & $\begin{array}{c}\mathrm{IR} / v(\mathrm{KBr}) \mathrm{cm}^{-1}: 3310-3450,3030,1609,1170, \text { and } 1150 \\
{ }^{1} \mathrm{H} \text { NMR }(\mathrm{DMSO}-\mathrm{d} 6,500 \mathrm{MHz}), \delta(\mathrm{ppm}): 13.31(\mathrm{~s}, 2 \mathrm{H}), 8.73(\mathrm{~s}, 2 \mathrm{H}), 8.07(\mathrm{~d}, 4 \mathrm{H}), 7.42(\mathrm{~m}, \\
4 \mathrm{H}), 7.36(\mathrm{~m}, 2 \mathrm{H}), 7.27(\mathrm{q}, 4 \mathrm{H}) \text {, and } 6.22(\mathrm{t}, 2 \mathrm{H}) . \mathrm{MS}(\mathrm{EI}, \mathrm{m} / \mathrm{z}): 420(\mathrm{M}+, 40) \text { and } 392(18) .\end{array}$ \\
\hline
\end{tabular}




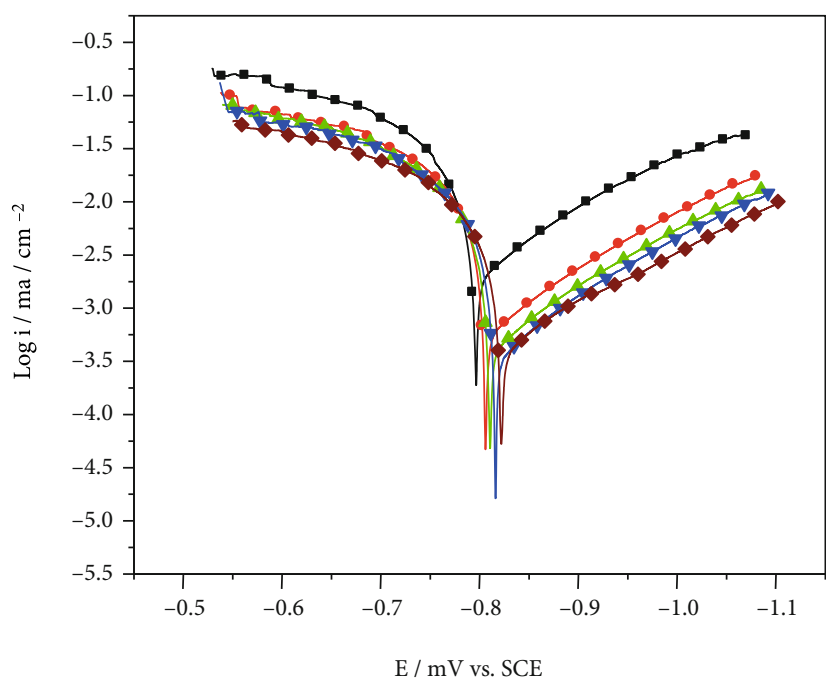

(a)

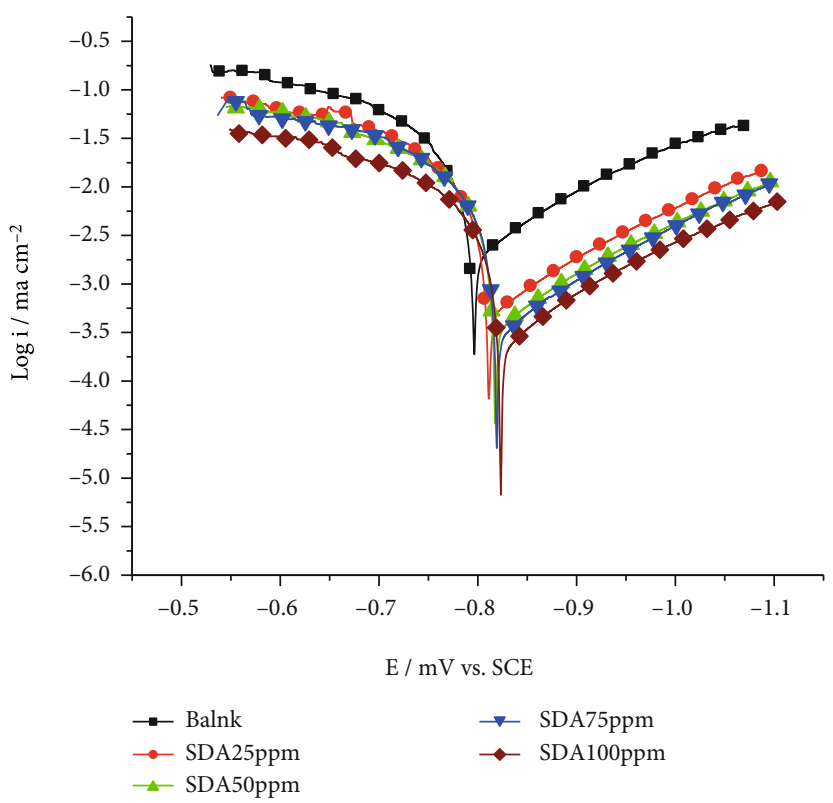

(b)

Figure 1: Tafel plots for (a) N,N ${ }^{\prime}$-bis(salicylidine)- $4,4^{\prime}$-diaminostilbene (SDS). (b) N, $\mathrm{N}^{\prime}$-bis(Salicylidine)-4, $4^{\prime}$-diaminoazobenzene (SDA).

TABLE 3: PDP parameters of N, $N^{\prime}$-bis(salicylidine)-4, $4^{\prime}$-diaminostilbene (SDS) and $\mathrm{N} \mathrm{N}^{\prime}$-bis(salicylidine)-4,4'-diaminoazobenzene(SDA).

\begin{tabular}{|c|c|c|c|c|c|c|c|}
\hline \multicolumn{8}{|l|}{ Tafel data } \\
\hline Inhibitor & Concentration (ppm) & OCP $(\mathrm{mV})$ & $-E_{\text {corr }}(\mathrm{mV}$ vs. SCE $)$ & $i_{\text {corr }}\left(\mathrm{mA} \mathrm{cm}^{-2}\right)$ & $b_{\mathrm{c}}\left(\mathrm{mV} \operatorname{dec}^{-1}\right)$ & $b_{\mathrm{a}}\left(\mathrm{mV} \operatorname{dec}^{-1}\right)$ & $\mu_{\mathrm{p}} \%$ \\
\hline \multirow{5}{*}{ SDS } & 0 & -796.5 & 741 & 4.091 & 179 & 65 & - \\
\hline & 25 & -805.8 & 769 & 1.105 & 201 & 68 & 73 \\
\hline & 50 & -810.6 & 778 & 1.023 & 209 & 69 & 75 \\
\hline & 75 & -815.9 & 781 & 0.859 & 212 & 72 & 79 \\
\hline & 100 & -821.8 & 790 & 0.736 & 215 & 74 & 82 \\
\hline \multirow{4}{*}{ SDA } & 25 & -810.9 & 780 & 0.941 & 211 & 76 & 77 \\
\hline & 50 & -817.3 & 785 & 0.859 & 214 & 78 & 79 \\
\hline & 75 & -818.8 & 788 & 0.736 & 216 & 82 & 82 \\
\hline & 100 & -823.2 & 792 & 0.532 & 221 & 89 & 87 \\
\hline
\end{tabular}




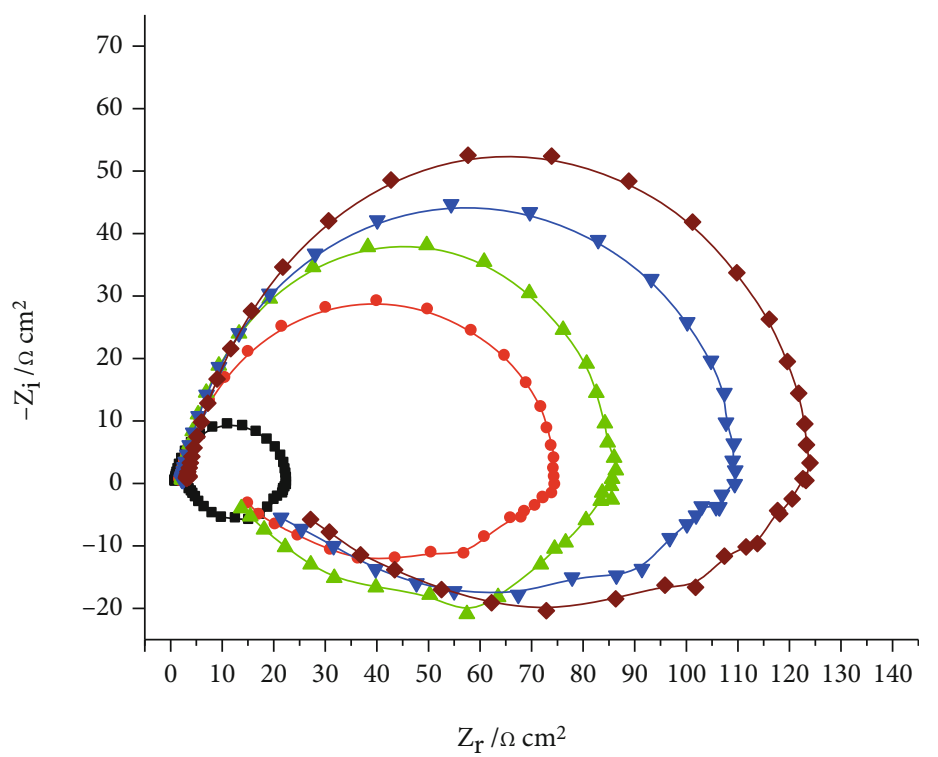

(a)

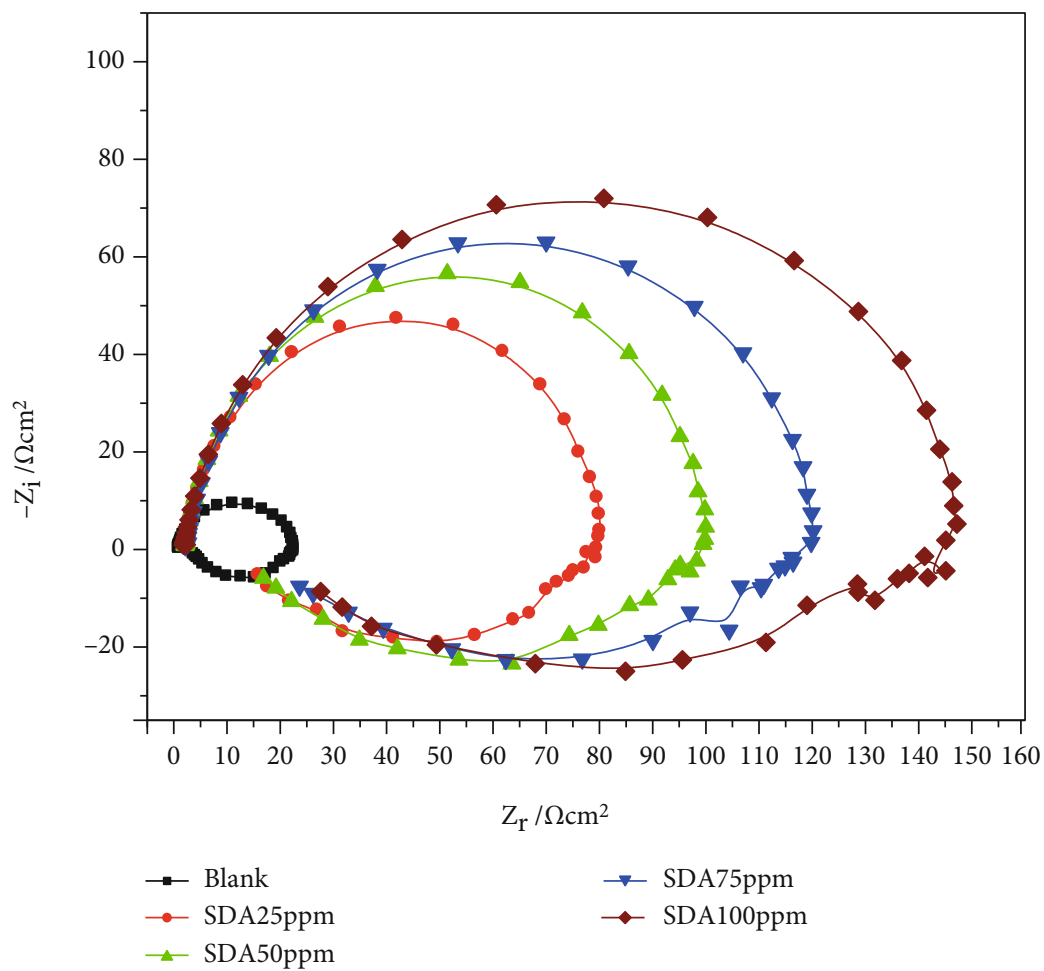

(b)

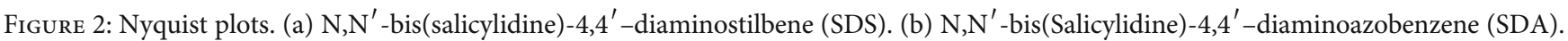

(iii) The electrodes were dried at $80^{\circ} \mathrm{C}$ for a half-hour in a thermostatic electric oven

(iv) The electrodes were preserved in a moisture-free desiccator

Prior to each weight loss experimental trial, the test specimens were weighed in Shimadzu AY220 electronic analytical weighing balance and the weight of the test specimens were recorded. After each experimental trial, the corroded test specimens were washed under running water and placed in $70 \% \mathrm{HNO}_{3}$ for $180 \mathrm{sec}$. The corroded test specimens were gently rubbed with a soft nylon brush for removing the corrosion product from the alloy surface. The corroded specimens were dried at $353 \mathrm{~K}$ temperature and were weighed up to $0.1 \mathrm{mg}$ accuracy and the loss in weight was noted down. Weight loss experiments were carried out in a constant temperature water bath fitted with an auto thermostat. 


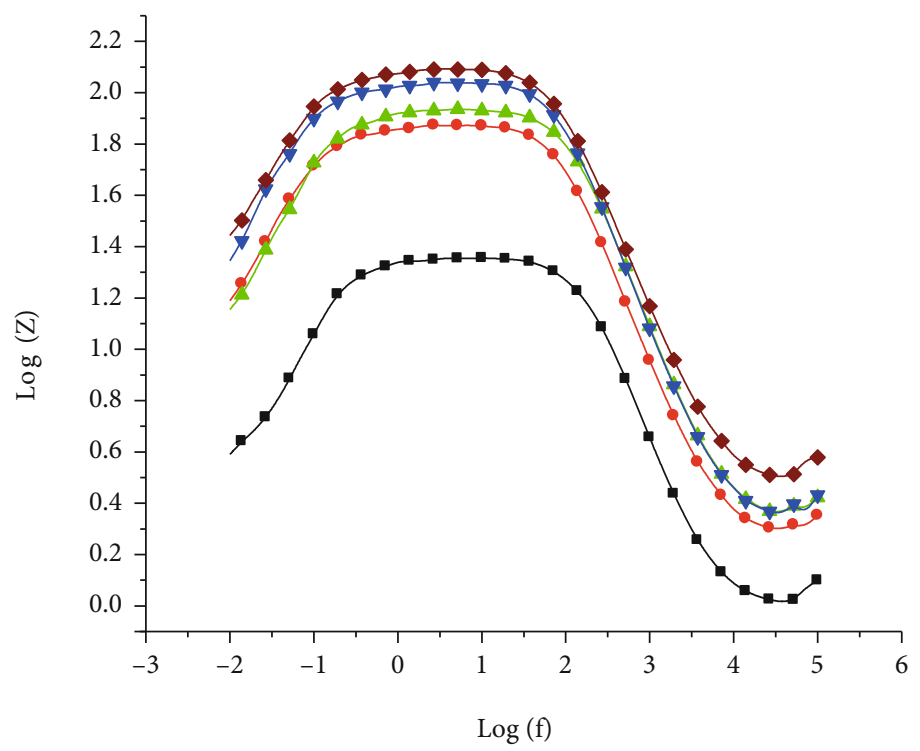

(a)

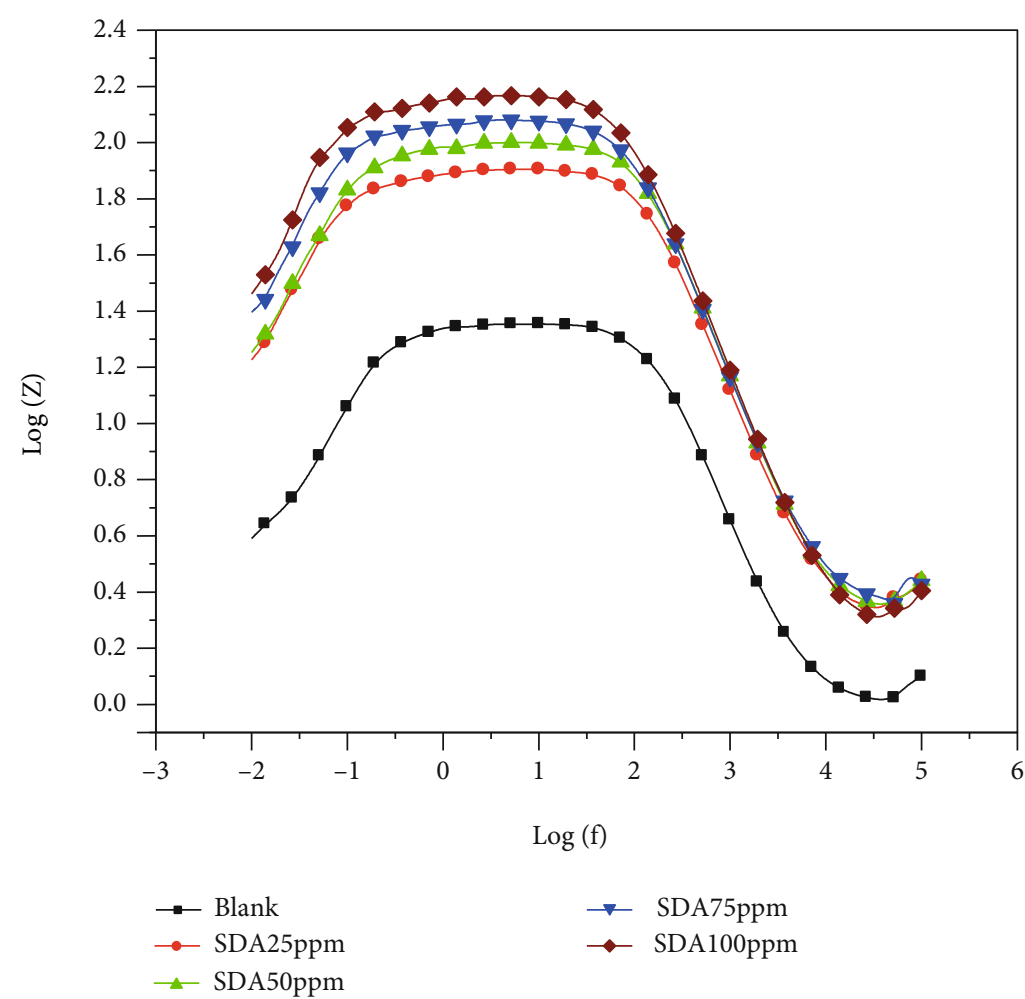

(b)

Figure 3: Bode plots. (a) N,N ${ }^{\prime}$-bis(salicylidine)-4, $4^{\prime}$-diaminostilbene (SDS). (b) N, $\mathrm{N}^{\prime}$-bis(Salicylidine)-4, $4^{\prime}$-diaminoazobenzene (SDA).

The weight loss experiment was carried out by immersing the test specimens' in

(i) $100 \mathrm{~mL} 1 \mathrm{M} \mathrm{HCl}$ solution

(ii) $100 \mathrm{~mL} 1 \mathrm{M} \mathrm{HCl}$ solution with various concentrations of Schiff bases-25 ppm through 100 ppm with increments of twenty-five ppm (iii) At the temperatures ranging from 303 through 333 $\pm 1 \mathrm{~K}$ with increments of $10 \mathrm{~K}$

(iv) At different exposure periods ranging from 2 through 8 hours with increments of two hours

The weight loss experiments were conducted in triplicate, and the average weight loss was calculated. 


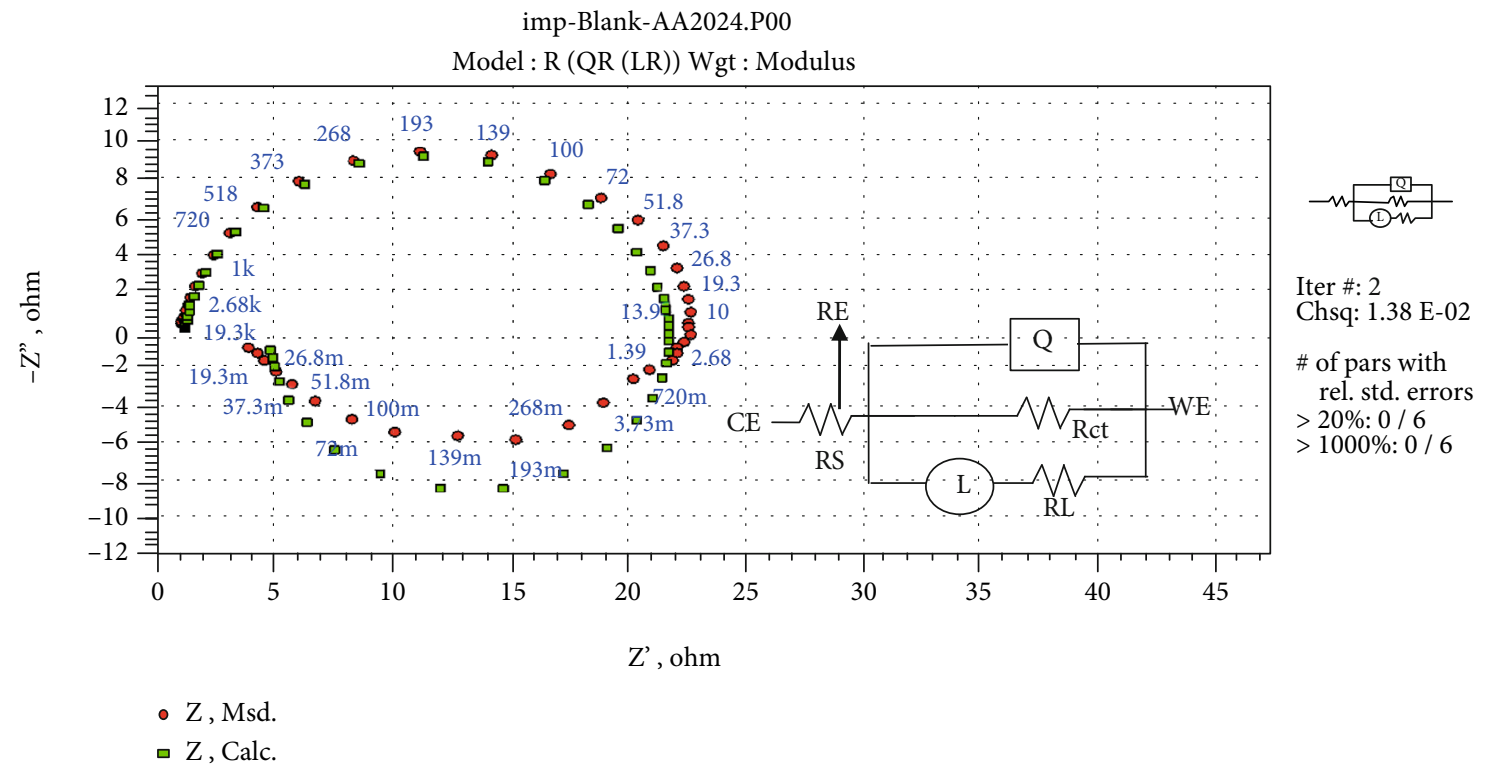

(a)

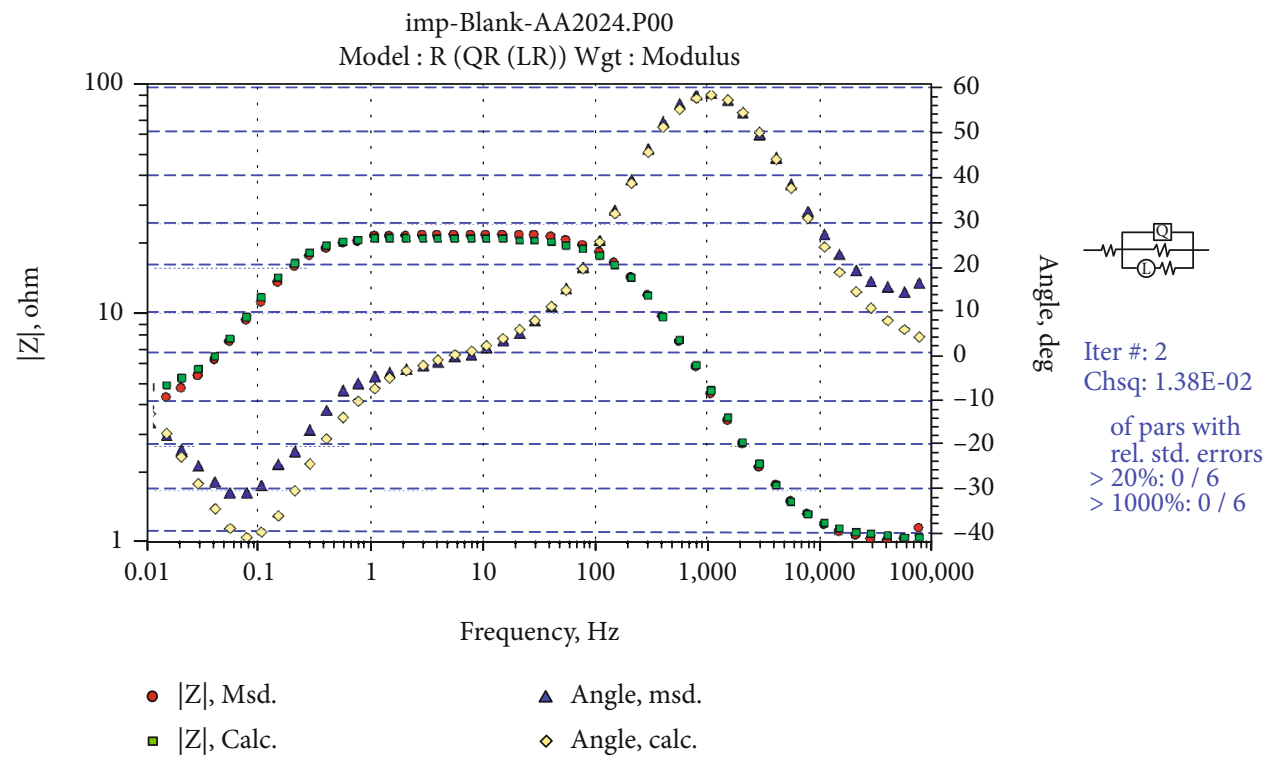

(b)

FIGURE 4: Equivalent circuit model used to fit EIS experimental data for AA2024 in $1 \mathrm{M} \mathrm{HCl}$ (a) Nyquist and (b) Bode plot.

3.2. Evaluation of Corrosion Rate (CR). The average corrosion rate (CR) was evaluated as per ASTM equation (1) in mmpy, where $K$ is a constant $\left(8.76 \times 10^{4}\right)$, $W$ is the weight loss in grams, $D$ is the density in $\mathrm{g} / \mathrm{cm}^{3}, A$ is the surface area of test specimen in $\mathrm{cm}^{2}$, and $T$ is the time of exposure in hours.

$$
\mathrm{CR}=\frac{\mathrm{W} \times \mathrm{K}}{\mathrm{TAD}}
$$

3.3. Calculation of Inhibition Efficiency. Inhibition efficiency percentage $\left(\mu_{\mathrm{WL} \%}\right)$ and degree of surface coverage $(\theta)$ were calculated using the weight loss of uninhibited $W_{0}$ and $W_{i}$ inhibited test specimen using equations (2) and (3), respec- tively,

$$
\begin{gathered}
\mu_{\mathrm{WL}} \%=\frac{W_{0}-W_{i}}{W_{0}} \times 100, \\
\theta=\frac{W_{0}-W_{i}}{W_{0}} .
\end{gathered}
$$

3.4. Electrochemical Measurements. The electrochemical measurements were performed in a 3-electrode pyrex glass electrochemical cell using CHI660c electrochemical workstation. The aluminum alloy 2024 test specimen with a surface area of $1 \mathrm{~cm}^{2}$, a saturated calomel electrode (SCE) attached to a Luggin capillary to keep the IR drop minimized, and platinum electrode has been used as working electrode, reference, 
TABLE 4: EIS data using SDS and SDA as inhibitors.

\begin{tabular}{lcccccccccc}
\hline Electrochemical impedance spectroscopy data \\
\hline Inhibitor & $\begin{array}{c}\text { Concentration } \\
(\mathrm{ppm})\end{array}$ & $R_{S}\left(\Omega \mathrm{cm}^{-2}\right)$ & $R_{\mathrm{ct}}\left(\Omega \mathrm{cm}^{-2}\right)$ & $R_{L}\left(\Omega \mathrm{cm}^{-2}\right)$ & $L\left(\mathrm{Hcm}^{-2}\right)$ & $\omega(\mathrm{Hz})$ & $\mathrm{CPE}\left(\mu \mathrm{F} \mathrm{cm}^{-2}\right)$ & $N$ & $\left.\mathrm{Cdl}(\mu \mathrm{F} \mathrm{cm})^{-2}\right)$ & $\mu_{\mathrm{Rct}} \%$ \\
& 0 & 1.14 & 09 & 1.41 & 26.1 & 3.7 & 119 & 0.8805 & 67 & - \\
& 25 & 1.19 & 34.0 & 22.1 & 113 & 27 & 34 & 0.9138 & 24.1 & 73.5 \\
\multirow{4}{*}{$\mathrm{SDS}$} & 50 & 1.29 & 38.5 & 30.2 & 141 & 35 & 29 & 0.9216 & 22.3 & 76.6 \\
& 75 & 1.34 & 45.2 & 45.3 & 167 & 46 & 25 & 0.9281 & 19.1 & 80.1 \\
& 100 & 1.38 & 52.9 & 52.4 & 291 & 51 & 22 & 0.9299 & 14.3 & 83.0 \\
& 25 & 1.29 & 40.5 & 11.3 & 161 & 44 & 29 & 0.9251 & 25.7 & 77.8 \\
& 50 & 1.32 & 44.6 & 32.9 & 227 & 55 & 17 & 0.9273 & 13.5 & 79.8 \\
$\mathrm{SDA}$ & 1.38 & 52.0 & 39.3 & 281 & 62 & 15 & 0.9288 & 12.1 & 82.8 \\
& 75 & 1.32 & 66.7 & 40.3 & 301 & 71 & 13 & 0.9332 & 9.8 & 86.5 \\
\hline
\end{tabular}

and auxiliary electrodes, respectively. The surface area of the test specimen was cleaned as explained under material and methods. The open circuit potential, potentiodynamic polarization (PDP), and electrochemical impedance spectroscopy (EIS) experiments were carried out in triplicates, and average results were considered for analysis.

3.5. Potentiodynamic Polarization (PDP) Measurements. The AA2024 test specimens were polarized in the potential range between -250 and $+250 \mathrm{mV}$ with respect to OCP at $1 \mathrm{mV} / \mathrm{s} \mathrm{scan}$ rate to obtain Tafel plots. The corrosion current densities $I^{\circ}$ corr and $I_{\text {corr }}$ in the absence and presence of inhibitor, respectively, were obtained by extrapolating linear segments of anodic and cathodic curves from plots to corrosion potential $\left(E_{\text {corr }}\right)$. The efficiency of inhibition was calculated using equation (4),

$$
\mu_{P} \%=\frac{I_{\text {corr }}^{\circ}-I_{\text {corr }}}{I_{\text {corr }}^{\circ}} \times 100 .
$$

3.6. Electrochemical Impedance Spectroscopy (EIS) Measurements. The electrochemical impedance spectroscopy experiments were conducted with $10 \mathrm{mV}$ peak-peak amplitude and AC signal at OCP, and frequency varied between $100 \mathrm{kHz}$ and 1.0 MHz. The impedance data was analyzed using Nyquist plot and Bode plots. Data fitting for obtaining an equivalent circuit model was performed using Echem software ZSimpWin v3.21.

The inhibition efficiency $\mu_{R c t} \%$ was calculated using charge transfer resistance data in inhibited $R_{\mathrm{ct}}^{i}$ and uninhibited $R_{c t}^{\circ}$ solutions, respectively, using equation (5).

$$
\mu_{R \mathrm{ct}} \%=\frac{R_{\mathrm{ct}}^{i}-R_{\mathrm{ct}}^{\circ}}{R_{\mathrm{ct}}^{\mathrm{i}}} \times 100
$$

3.7. Evaluation of Thermodynamic and Adsorption Isotherm Parameters. The thermodynamic activation parameters were obtained using weight loss experimental data.

3.8. Activation Parameters. Activation parameters like activation energy $\left(E_{a}\right)$, enthalpy of activation $\left(\Delta H^{*}\right)$, and entropy of activation $\left(\Delta S^{*}\right)$ for the dissolution of metal in the acid medium in the presence of various concentrations of inhibitor were calculated from the Arrhenius equation (6) and transition state equations (7).

$$
\begin{gathered}
\log (\mathrm{CR})=\frac{-E_{a}}{2.303 R T}+\mathrm{A}, \\
\mathrm{CR}=\frac{R T}{N h} \exp \left(\frac{\Delta \mathrm{S}^{*}}{R}\right) \exp \left(-\frac{\Delta H^{*}}{R T}\right) .
\end{gathered}
$$

3.9. Adsorption Isotherms. The surface coverage $(\theta)$ values derived from weight loss data for different concentrations of Schiff bases were tested graphically to best fit one of the adsorption isotherms from among Langmuir, Freundlich, and Temkin isotherms. With $C_{(\text {inh })}$ indicating inhibitor concentration, Langmuir's isotherm $\left(C_{(\text {inh }) l} \theta\right.$ vs. $\left.C_{(\text {inh })}\right)$ with a linear regression coefficient value nearest to one was found to be the fitting best. Langmuir adsorption isotherm is expressed as follows equation (8) with $K_{(\mathrm{ads})}$ representing equilibrium constant for adsorption and desorption:

$$
\frac{C_{\mathrm{inh}}}{\theta}=\frac{1}{K_{(\mathrm{ads})}}+C_{\mathrm{inh}} .
$$

3.9.1. Standard Free Energy of Adsorption $\left(\Delta G_{a d s}^{\circ}\right)$. The $\Delta$ $G_{\text {ads }}^{\circ}$ was calculated using $K_{(\mathrm{ads})}$ that was derived from straight-line intercepts on the $C_{(\mathrm{inh}) l} \theta$ axis and equation (9).

$$
\Delta G_{\mathrm{ads}}^{\circ}=-\mathrm{R} \operatorname{Tln}\left(55.5 K_{\mathrm{ads}}\right) .
$$

3.10. Standard Enthalpy and Entropy of Adsorption ( $\Delta H^{\circ}$ ads and $\left.\Delta S_{a d s}^{\circ}\right)$. The standard enthalpy of adsorption $\left(\Delta H^{\circ}\right.$ ads $)$ and standard entropy of adsorption $\left(\Delta S_{\text {ads }}^{\circ}\right)$ were derived by plotting a graph $\ln K_{(\mathrm{ads})}$ vs. $1 / T$ and by measuring straight lines with a slope equal to $\left(-\Delta H^{\circ}{ }_{\text {ads }} R\right)$ and intercept $\left(\Delta S_{\text {ads }}^{\circ} / \mathrm{R}+\ln 1 / 55.5\right)$.

3.11. Scanning Electron Microscopic (SEM) Studies. The surface morphology of corroded and inhibited aluminum alloy 2024 test specimens was analyzed by JSM-840A-JEOL model scanning electron microscope. Following cases of $\mathrm{Al}$ alloy specimen were considered for the studies: 
TABLE 5: Weight loss data related to SDS and SDA.

\begin{tabular}{|c|c|c|c|c|c|c|}
\hline Weight loss data & & & & & & \\
\hline \multirow[t]{10}{*}{ Inhibitor } & $\begin{array}{l}\text { Temperature } \\
(\mathrm{K})\end{array}$ & $\begin{array}{l}\text { Concentration } \\
(\mathrm{ppm})\end{array}$ & $\begin{array}{l}\text { Weight loss } \\
\quad(\mathrm{mg})\end{array}$ & $\begin{array}{c}\text { C.R. } \\
(\mathrm{mmpy})\end{array}$ & $\mu_{\mathrm{WL}} \%$ & $\Theta$ \\
\hline & & Blank & 128.7 & 197.0 & - & - \\
\hline & & 25 & 36.0 & 55.1 & 72 & 0.72 \\
\hline & 303 & 50 & 30.9 & 47.3 & 76 & 0.76 \\
\hline & & 75 & 25.7 & 39.4 & 80 & 0.80 \\
\hline & & 100 & 21.9 & 33.5 & 83 & 0.80 \\
\hline & & Blank & 288.0 & 440.8 & - & - \\
\hline & & 25 & 99.6 & 152.5 & 63 & 0.63 \\
\hline & 313 & 50 & 90.8 & 139.0 & 65 & 0.65 \\
\hline & & 75 & 79.1 & 121.1 & 68 & 0.68 \\
\hline \multirow{18}{*}{$\mathrm{N}, \mathrm{N}^{\prime}$-bis(Salicylidine)-4,4-'diaminostilbene (SDS) } & & 100 & 67.4 & 103.1 & 72 & 0.73 \\
\hline & & Blank & 578.2 & 884.9 & - & - \\
\hline & & 25 & 242.8 & 371.6 & 56 & 0.56 \\
\hline & 323 & 50 & 221.7 & 339.2 & 59 & 0.59 \\
\hline & & 75 & 203.7 & 311.7 & 64 & 0.64 \\
\hline & & 100 & 185.7 & 284.2 & 67 & 0.67 \\
\hline & & Blank & 989.7 & 1514.6 & - & - \\
\hline & & 25 & 445.4 & 681.6 & 51 & 0.51 \\
\hline & 333 & 50 & 425.6 & 651.3 & 54 & 0.54 \\
\hline & & 75 & 386.0 & 590.7 & 57 & 0.57 \\
\hline & & 100 & 356.3 & 545.3 & 62 & 0.62 \\
\hline & & 25 & 33.5 & 51.2 & 75 & 0.75 \\
\hline & 303 & 50 & 25.7 & 39.4 & 80 & 0.80 \\
\hline & & 75 & 21.9 & 33.5 & 83 & 0.83 \\
\hline & & 100 & 18.0 & 27.6 & 86 & 0.86 \\
\hline & & 25 & 87.9 & 134.5 & 68 & 0.68 \\
\hline & 313 & 50 & 76.2 & 116.6 & 70 & 0.70 \\
\hline & 313 & 75 & 67.4 & 103.1 & 73 & 0.73 \\
\hline \multirow{9}{*}{$\begin{array}{l}\text { N,N } N^{\prime} \text {-bis(Salicylidine) }-4,4^{\prime} \text {-diamino azobenzene } \\
\text { (SDA) }\end{array}$} & & 100 & 58.6 & 89.7 & 76 & 0.76 \\
\hline & & 25 & 219.7 & 336.3 & 59 & 0.59 \\
\hline & 323 & 50 & 202.4 & 309.7 & 64 & 0.64 \\
\hline & J & 75 & 185.0 & 283.2 & 67 & 0.67 \\
\hline & & 100 & 150.3 & 230.1 & 72 & 0.72 \\
\hline & & 25 & 425.6 & 651.3 & 54 & 0.54 \\
\hline & 333 & 50 & 376.1 & 575.6 & 57 & 0.57 \\
\hline & ננJ & 75 & 346.4 & 530.1 & 61 & 0.61 \\
\hline & & 100 & 306.8 & 469.5 & 66 & 0.66 \\
\hline
\end{tabular}

(i) Polished samples

(ii) Samples corroded in $1 \mathrm{M} \mathrm{HCl}$ with no inhibitors

(iii) Samples inhibited in $1 \mathrm{M} \mathrm{HCl}$ with $100 \mathrm{ppm}$ of Schiff bases

\section{Results and Discussion}

4.1. Potentiodynamic Polarization Studies. The potentiodynamic polarization studies of AA2024 alloy were conducted in $1 \mathrm{M} \mathrm{HCl}$ at $303 \pm 1 \mathrm{~K}$ in the absence and presence of SDS and SDA as inhibitors, with $25,50,75$, and 100 ppm concentrations. The experimental data were used to plot the Tafel plots as depicted in Figures 1(a) and 1(b) for SDS and SDA, respectively. The corresponding PDP parameters, corrosion potential $\left(E_{\text {corr }}\right)$, corrosion current density $\left(I_{\text {corr }}\right)$, and cathodic and anodic Tafel slopes $\left(b_{a}\right.$ and $\left.b_{c}\right)$ derived from the Tafel plots are presented in Table 3 . For each given concentration of SDS and SDA, the inhibition efficiency ( $\mu \mathrm{p} \%)$ of inhibitors was derived using equation (4).

The PDP results showed the curves being shifted to the lower current density side when inhibitor concentration 


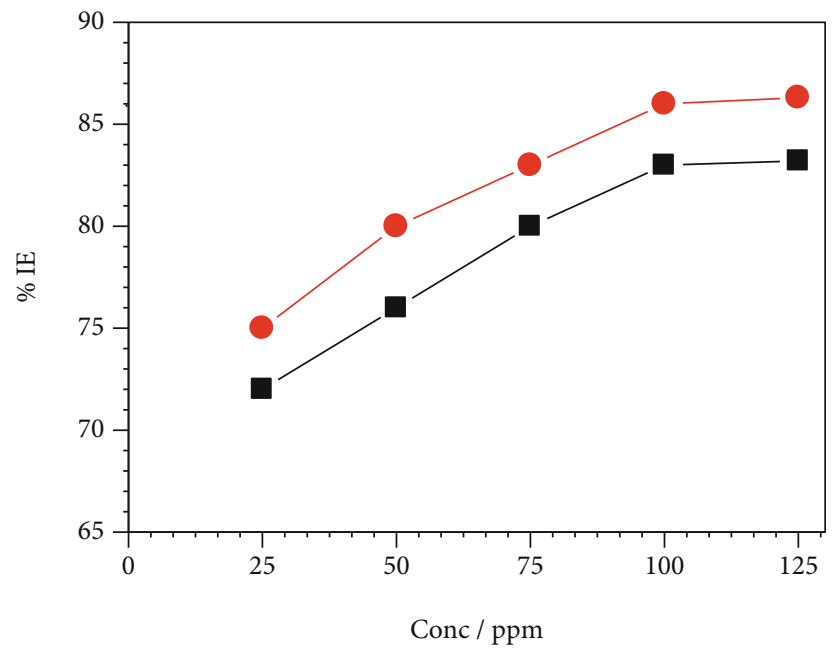

(a)

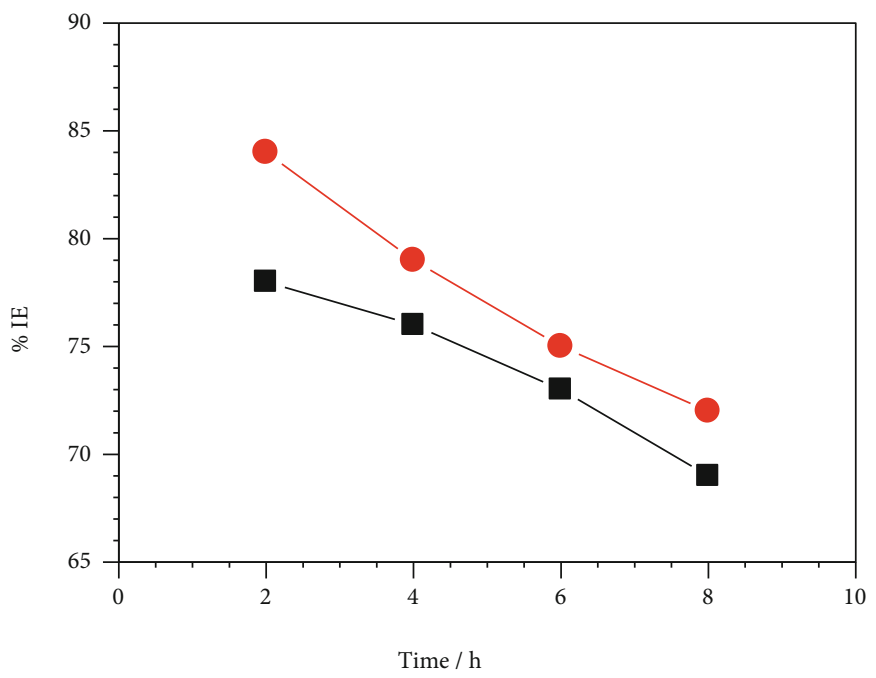

(b)

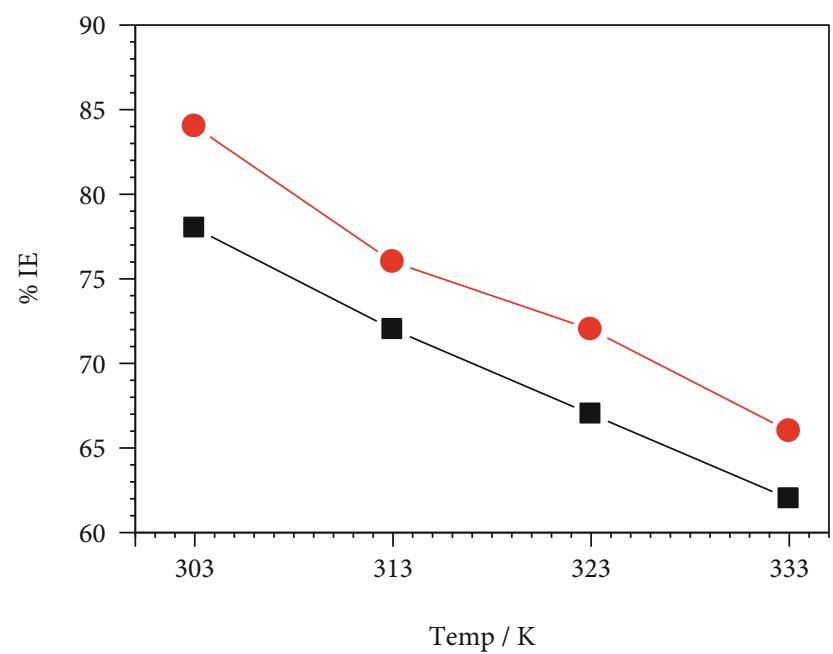

$\rightarrow-$ SDS

- SDA

(c)

FIgURE 5: (a) Influence of inhibitor concentration, (b) influence of immersion time, and (c) influence of temperature on the \% IE. 


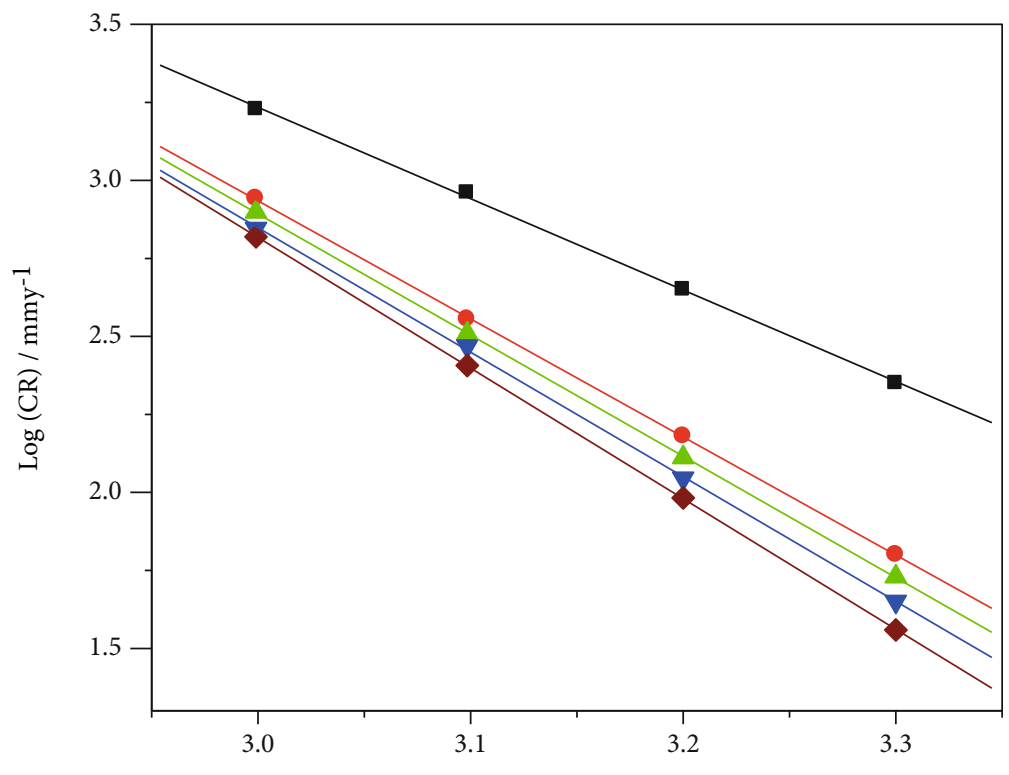

$(1 / \mathrm{T}) 10^{3} / \mathrm{K}^{-1}$

(a)

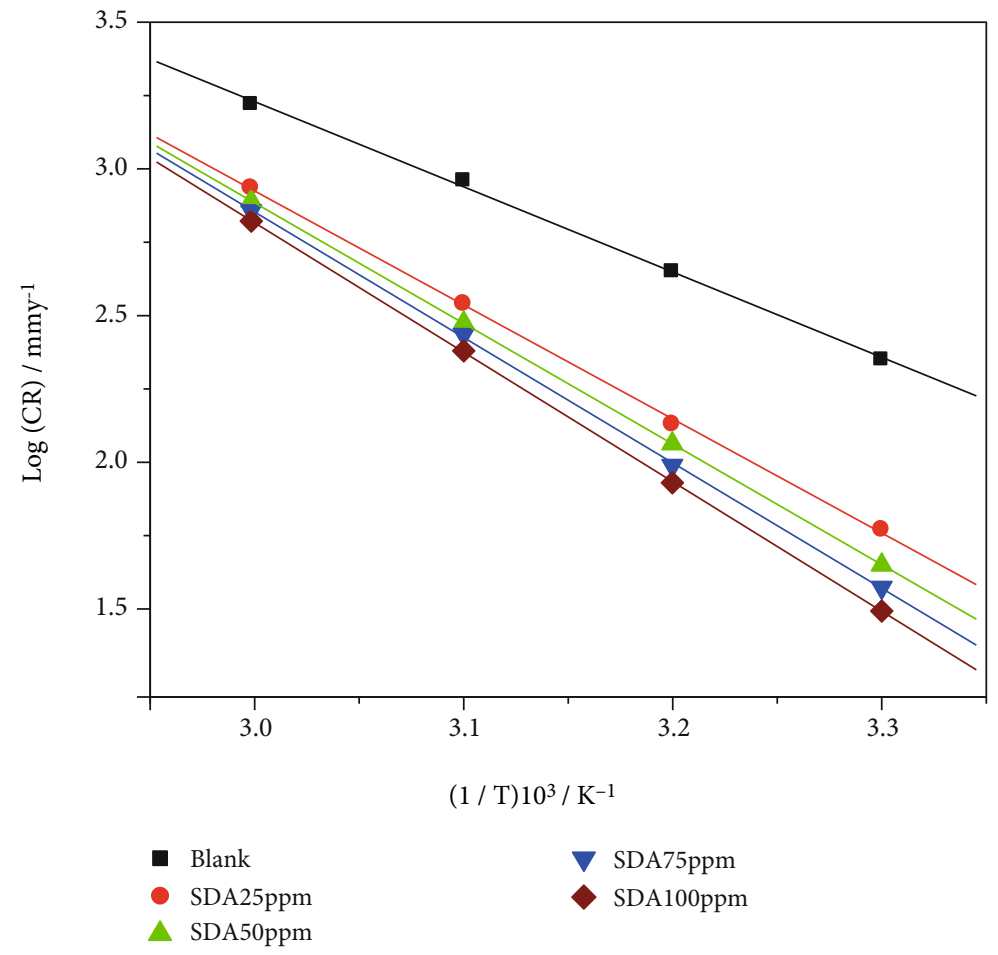

(b)

FIgUre 6: Arrhenius plot related to (a) SDS and (b) SDA.

was increased and the corrosion potential $\left(E_{\text {corr }}\right)$ values to not having shown any major shift(within $85 \mathrm{mV}$ with respect to $E_{\text {corr }}$ of blank solution). This confirms the characteristics of mixed type inhibitors [31,32].

The PDP results also show the cathodic curves which have been more polarized. This suggests that the cathodic reduction rate was retarded, and diamines were the influencers of cathodic reactions compared to anodic and hence suggest the characteristics of cathodic inhibitors [33, 34] which could have occurred because of protonated diamine molecules getting adsorbed on cathodic and anodic sites. The inhibition efficiency of SDA was found to be the most efficient than SDS at different concentrations.

4.2. Electrochemical Impedance Spectroscopy Studies. The Nyquist and Bode plots for the corrosion inhibition of 
TABLE 6: Thermodynamic parameters related to SDS and SDA.

\begin{tabular}{|c|c|c|c|c|}
\hline \multicolumn{5}{|l|}{ Thermodynamic data } \\
\hline Schiff base inhibitors & Concentration (ppm) & $\begin{array}{c}E a \\
\left(\mathrm{kJmol}^{-1}\right)\end{array}$ & $\begin{array}{c}\Delta H^{*} \\
\left(\mathrm{kJmol}^{-1}\right)\end{array}$ & $\Delta S^{*}\left(\mathrm{~J} \mathrm{~mol}^{-1} \mathrm{~K}^{-1}\right)$ \\
\hline \multirow{5}{*}{$\mathrm{N}, \mathrm{N}^{\prime}$-bis(Salicylidine)-4,4-'diaminostilbene (SDS) } & Blank & 58.12 & 53.09 & -25.15 \\
\hline & 25 & 73.64 & 72.37 & 25.23 \\
\hline & 50 & 75.22 & 73.89 & 29.42 \\
\hline & 75 & 77.53 & 74.94 & 30.15 \\
\hline & 100 & 81.17 & 75.57 & 32.54 \\
\hline \multirow{4}{*}{$\mathrm{N}, \mathrm{N}^{\prime}$-bis(Salicylidine)-4,4'diamino azobenzene } & 25 & 75.87 & 72.74 & 27.71 \\
\hline & 50 & 79.78 & 74.28 & 29.94 \\
\hline & 75 & 82.19 & 75.63 & 30.74 \\
\hline & 100 & 85.48 & 77.31 & 37.56 \\
\hline
\end{tabular}

AA2024 alloy in $1 \mathrm{M} \mathrm{HCl}$ without inhibitors and with different concentrations of SDS and SDA are presented in Figures 2(a), 2(b), 3(a), and 3(b), respectively. The Nyquist diagrams showed semicircular curves which reveal that the corrosion process is under charge transfer control. In general, the shape of the Nyquist plots is with a large capacitive loop at higher frequencies and an inductive loop at lower frequencies. Some researchers have also reported similar EIS plots [35-41] for aluminum alloys in hydrochloric acid. The depressed semicircular curves having center under real axis behavior termed as dispersing effect [42, 43] are the property of solid electrode.

An equivalent circuit model fitted for simulating the measured impedance data of AA2024 are depicted with standard errors in Figures 4(a) and 4(b) for Nyquist and Bode plot, respectively. The equivalent circuit model which contains $R_{s}, R_{\mathrm{ct}}, R_{L}$, and $L$ correspondingly represent solution resistance, charge transfer resistance, and inductance resistance and inductance $L$, respectively. The circuit model also contains the constant phase element CPE (Q).

The constant phase element (CPE) in the equivalent circuit can be substituted by the respective capacitor of $C_{\mathrm{dl}}$ in order to give a more accurate fit, which is a frequencydependent element and related to surface roughness. The impedance function of a CPE is calculated using equation (10) [44],

$$
Z_{\mathrm{CPE}}=\frac{1}{\left(Y_{0} j \omega\right)^{n}},
$$

where $Y_{0}$ is the CPE magnitude. $j$ is the CPE exponent (frequency-independent). $\omega$ is the angular frequency for which $-Z^{\prime \prime}$ reaches its maximum value. $n$ is the value that depends on surface morphology having range: $-1 \leq n \leq 1$. $Y_{0}$ and $n$ are found from the equation shown by Mansfield et al. [45].

The double-layer capacitance $\left(C_{\mathrm{dl}}\right)$ is derived using angular frequency $\omega_{\max }$ with imaginary component of impedance reaching a maximum at $Z_{\text {imax }}$ by equation (11)
[46]:

$$
C_{\mathrm{dl}}=Y_{0}\left(\omega_{\max }\right)^{n-1}
$$

The EIS spectra of uninhibited and inhibited aluminum alloy AA2024 are depressed. This kind of deviation is referred to as frequency dispersion and has been attributed to nonhomogeneous solid alloy surfaces. Assumption of a simple $\left(R_{\mathrm{ct}}-C_{\mathrm{dl}}\right)$ is usually a poor approximation for systems showing depressed semicircle behavior due to nonideal capacitive behavior of solid electrodes surface [47]. The CPE [48], $C_{\mathrm{dl}}$, and $\mu R_{\mathrm{ct}} \%$ were evaluated by equations (5), (10), and (11). The electrochemical impedance parameters $R_{s}$, $R_{\mathrm{ct}}, R_{L}, L, \omega, \mathrm{CPE}, n$, and the inhibition efficiency evaluated by $R_{c t}$ and $C_{\mathrm{dl}}$ values are tabulated in Table 4 .

The charge transfer resistance $\left(R_{\mathrm{ct}}\right)$ of the inhibited alloy increased and double-layer capacitance $\left(C_{\mathrm{dl}}\right)$ decreased with an increase in inhibitor concentration. This is because the adsorption of inhibitor molecules on to the alloy which forms physical barrier and block either or both anodic and cathodic reactions thereby reducing the alloy reactivity. This is maybe due to changes in the electric double layer at the solution and alloy surface interface. The reduction in double-layer capacitance $\left(C_{\mathrm{dl}}\right)$ can be caused by a decrease in the local dielectric constant and or an increase in the thickness of the electrical double layer. This suggests that the inhibitor molecules inhibit the aluminum alloy surface by adsorption at the alloy acid interface.

It is perceptible that the inhibition efficiency increases with an increase in the concentration of inhibitor, which is in concurrence with the potentiodynamic polarization outcome. The charge transfer resistance $\left(R_{\mathrm{ct}}\right)$ and double-layer capacitance $\left(C_{\mathrm{dl}}\right)$ values indicate that the AA2024 alloy surface is more efficiently inhibited by SDA than SDS.

4.3. Weight Loss Studies. The weight loss studies of AA2024 alloy in $1 \mathrm{M} \mathrm{HCl}$ in the absence and presence of SDS and SDA were carried out at different inhibitor concentrations, immersion time, and solution temperature. The weight loss experimental parameters weight loss $(\Delta \mathrm{w})$, percentage of inhibition efficiency $\left(\mu_{\mathrm{WL}} \%\right)$, corrosion rate (C.R.) in mmpy, 


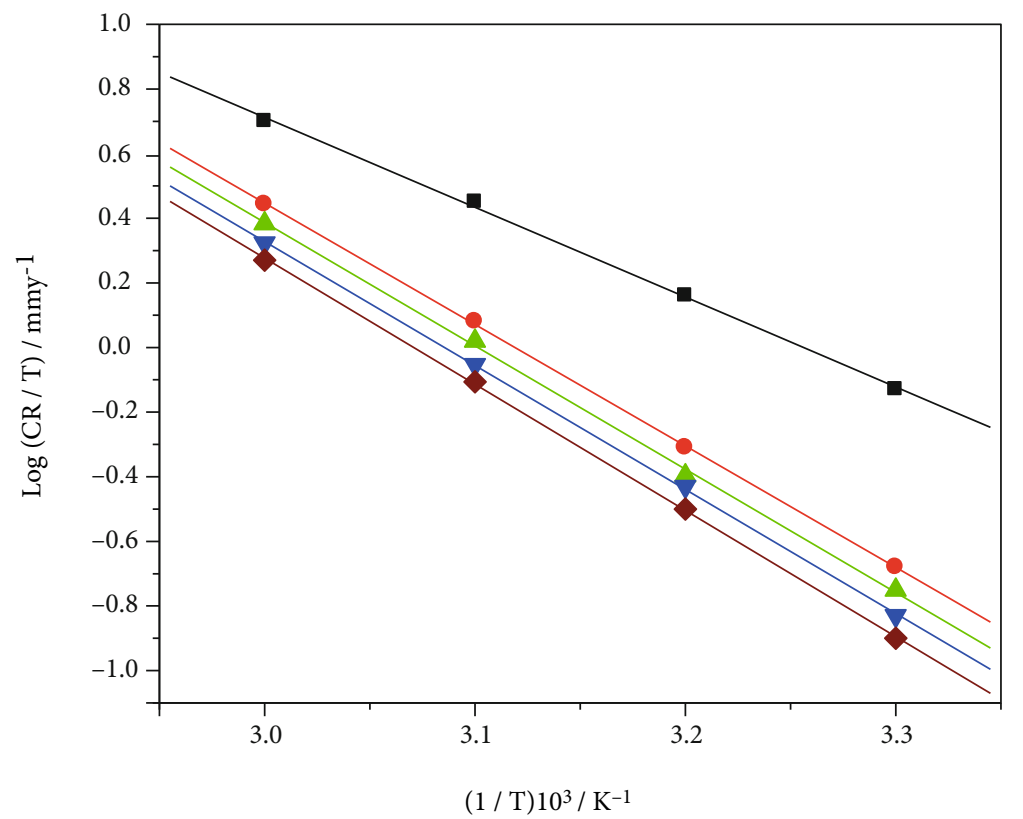

(a)

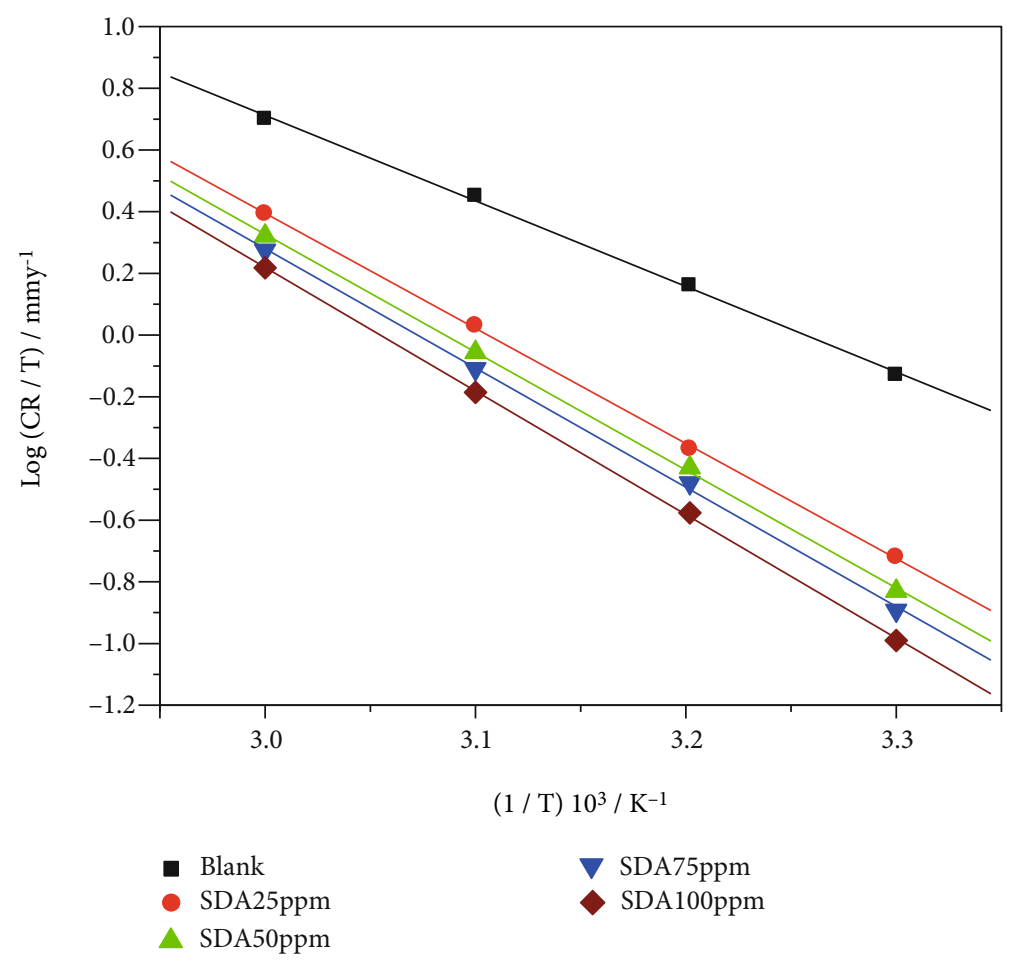

(b)

FIGURE 7: Thermodynamic plot related to (a) SDS and (b) SDA.

and degree of surface coverage $(\theta)$ calculated for 2 hours exposure time and at different temperatures are presented in Table 5 for SDS and SDA correspondingly.

4.3.1. Effect of Inhibitor Concentration. The study revealed greater inhibition efficiency at higher inhibitor concentrations, which could be attributed to the formation of persistent film and covering a large surface area of the alloy by the inhibitor molecules. The maximum inhibition was achieved at $100 \mathrm{ppm}$ and beyond $100 \mathrm{ppm}$ concentration, and the inhibition efficiency was found to remain almost constant as shown in Figure 5(a).

4.3.2. Effect of Immersion Time. The inhibition efficiency of SDA and SDS decreased with an increase in immersion time from two to eight hours at $100 \mathrm{ppm}$ concentration is shown 


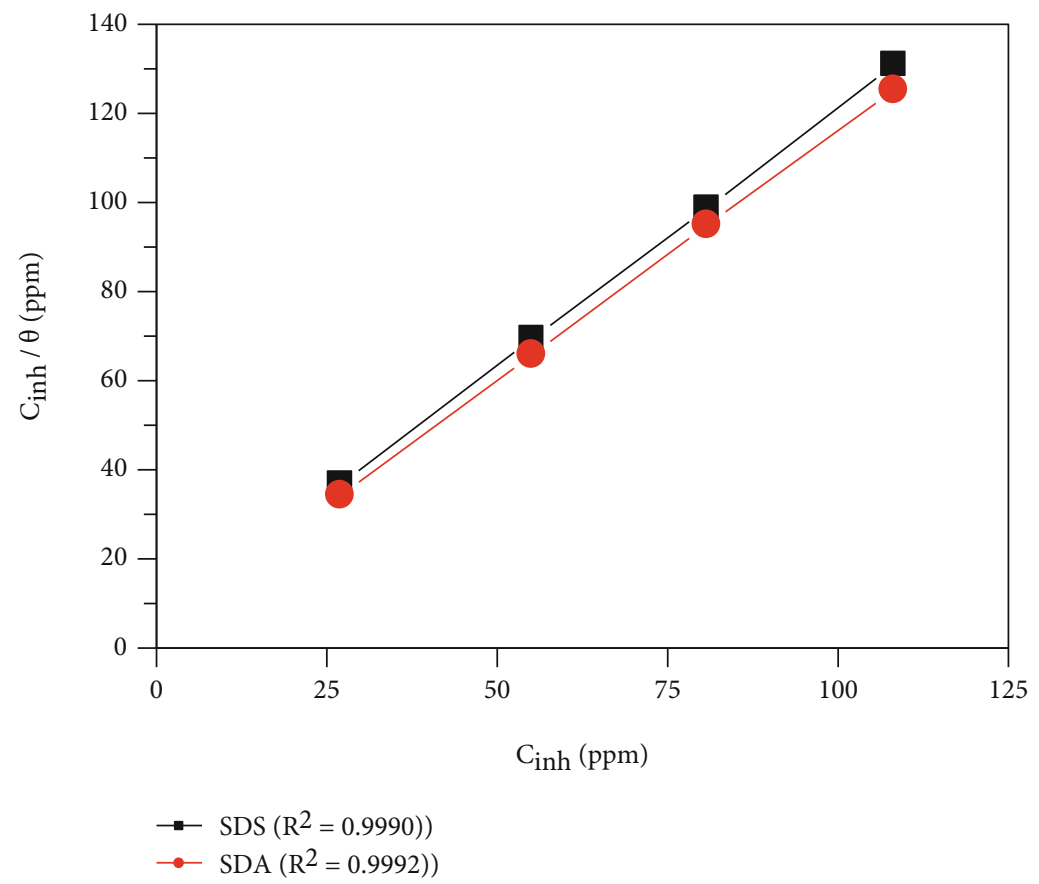

(a)

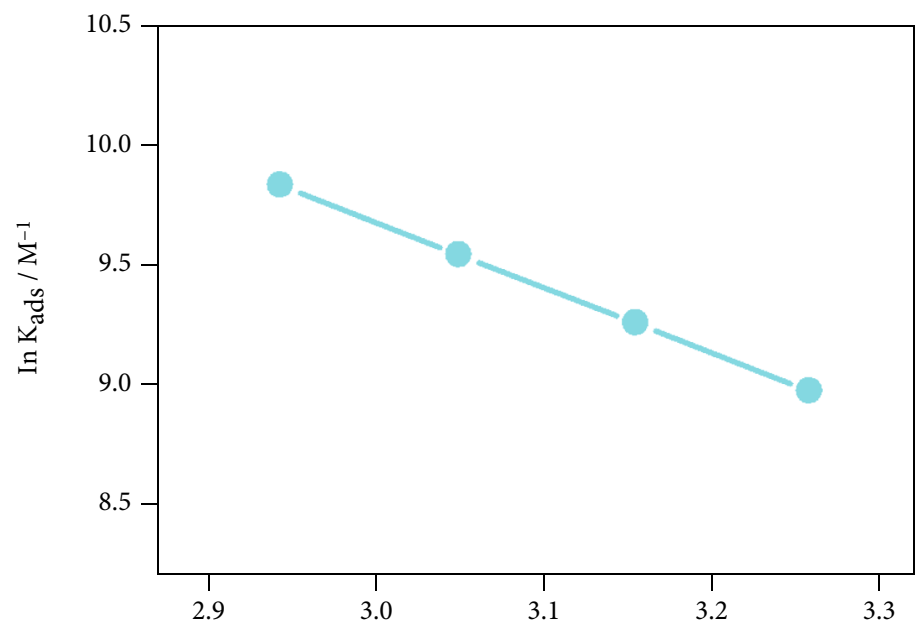

$(1 / \mathrm{T}) 10^{3} / \mathrm{K}^{-1}$

$\rightarrow$ SDS

$\rightarrow$ SDA

(b)

FIgURE 8: (a) Langmuir isotherm plot for SDS and SDA. (b) Heat of adsorption isotherm plot for SDS and SDA.

in Figure 5(b). This suggests desorption of inhibitor molecule over the surface of the alloy due to longer exposure time, resulting in the formation of lesser persistent film and an increase in cathodic reaction rate [49].

4.3.3. Effect of Temperature. The inhibition efficiency of the SDS and SDA was found to decrease with an increase in temperature between 303 and $333 \pm 1 \mathrm{~K}$ is shown in Figure 5(c). This could be attributed to inhibitor molecules getting desorbed from the alloy surface and aluminum alloy getting dissolved at faster rates with a rise in temperatures.

4.4. Thermodynamic Activation Parameters. The activation energy $\left(E_{a}\right)$ values were calculated from Arrhenius equation ((6)) using the measured slope values of graphs as presented in Figures 6(a) and 6(b), and the corresponding data is presented in Table 6.

The $\Delta S^{*}$ and $\Delta H^{*}$ values were calculated using the measured slope and intercept values of graphs shown in 
TABLE 7: Thermodynamic parameters related to SDS and SDA.

\begin{tabular}{|c|c|c|c|c|c|c|}
\hline \multicolumn{7}{|c|}{ Thermodynamic adsorption parameters } \\
\hline Schiff base inhibitor & Concentration (ppm) & Temperature (K) & $\begin{array}{c}K_{\mathrm{ads}} \\
\left(10^{3} \mathrm{M}^{-1}\right)\end{array}$ & $\begin{array}{c}\Delta G_{\text {ads }}^{\circ} \\
\left(\mathrm{kJmol}^{-1}\right)\end{array}$ & $\begin{array}{c}\Delta H^{\circ} \text { ads } \\
\left(\mathrm{kJmol}^{-1}\right)\end{array}$ & $\begin{array}{l}\Delta S_{\text {ads }}^{\circ} \\
\left(\mathrm{Jmol}^{-1}\right)\end{array}$ \\
\hline \multirow{4}{*}{$\begin{array}{l}\text { N,N' }{ }^{\prime} \text {-bis(Salicylidine)-4,4-' } \\
\text { diaminostilbene (SDS) }\end{array}$} & \multirow{4}{*}{100} & 303 & 15.8 & -34 & \multirow{5}{*}{29.2} & \multirow{5}{*}{203} \\
\hline & & 313 & 11.2 & -34 & & \\
\hline & & 323 & 8.34 & -35 & & \\
\hline & & 333 & 6.56 & -35 & & \\
\hline \multirow{4}{*}{$\begin{array}{l}\mathrm{N}, \mathrm{N}^{\prime} \text {-bis(Salicylidine) }-4,4^{\prime} \\
\text {-diamino azobenzene (SDA) }\end{array}$} & \multirow{4}{*}{100} & 303 & 24.7 & -35 & & \\
\hline & & 313 & 17.3 & -35 & \multirow{3}{*}{30.6} & \multirow{3}{*}{207} \\
\hline & & 323 & 11.5 & -36 & & \\
\hline & & 333 & 9.6 & -36 & & \\
\hline
\end{tabular}

Figures $7(\mathrm{a})$ and $7(\mathrm{~b})$ by transition state equation (7) and tabulated in Table 6.

The $E_{a}$ values of AA2024 in $1 \mathrm{M} \mathrm{HCl}$ in the presence of inhibitors SDS and SDA were found to be higher than those values obtained in the absence, depicting the increase in energy barrier for the corrosion reaction. The obtained $E_{a}$ values for the corrosion inhibition process are being above $20 \mathrm{~kJ} \mathrm{~mol}^{-1}$ and indicate that the inhibition process is wholly controlled by the surface reactions [50]. The inhibitor molecules get adsorbed onto the electrode surface leading to the development of a physical barrier being formed between the metal and corrosion media. This blocks the transfer of charge and reduces the reaction of alloy. An increase in inhibitor concentration leads to an increase in $E_{a}$ values due to physical adsorption on the metal surface by the inhibitor molecules [51]. In a sense, a physical barrier is formed due to the adsorption of inhibitor molecules on the surface of the electrode which reduces the alloy dissolution in electrochemical reactions [52].

The decrease in the inhibition efficiency of SDS and SDA inhibitor compounds with the increase in temperature can be attributed to a decrease in the extent of adsorption of the inhibitor on the alloy surface at elevated temperatures. The corresponding increase in corrosion rate is due to a larger area of matrix surface that gets exposed to the corrosion medium. The decrease in inhibition efficiency and increase in corrosion rate at elevated temperatures support the view that the inhibitor is adsorbed on the alloy surface through physisorption $[53,54]$. The endothermic nature of the corrosion process is indicated by the positive values of $\Delta H^{*}$. The rise in values of $\Delta S^{*}$ in presence of inhibitor concentration reveals that an increase in randomness occurred on going from reactants to the activated complex [55-57]. The adsorption of SDS and SDA inhibitor molecules on the AA2024 alloy surface could be regarded as quasisubstitution between the inhibitors molecules in the aqueous phase and water molecules on the electrode surface.

4.5. Adsorption Isotherms. In general, it is presumed that the adsorption of the inhibitor is the first step in the mechanism of inhibition in aggressive media at the alloy-solution interface. The adsorption isotherms furnish useful understandings into the mechanism of corrosion inhibition.
Theoretically, the adsorption process has been well regarded as a simple substitution adsorption process, in which an organic molecule in the aqueous phase substitutes the water molecules adsorbed on the alloy surface [58]. $\mathrm{H}_{2} \mathrm{O}_{(\mathrm{sol})}, \mathrm{Org}_{(\mathrm{sol})}, \mathrm{H}_{2} \mathrm{O}_{(\mathrm{ads})}$, and $\mathrm{Org}_{(\mathrm{ads})}$ are represented in equation (12), water and organic molecules present in solution, and those adsorbed with $x$ representing replaced water molecules count.

$$
\mathrm{xH}_{2} \mathrm{O}_{(\mathrm{ads})}+\mathrm{Org}_{(\mathrm{sol})} \longrightarrow \mathrm{Org}_{(\mathrm{ads})}+\mathrm{xH}_{2} \mathrm{O}_{(\mathrm{sol})}
$$

Understanding the adsorption mode and adsorption isotherm becomes necessary which provide deep insight into the interaction happening between inhibitor and alloy surface. From the weight loss experimental data obtained for different concentrations of inhibitor compounds, the surface coverage $(\theta)$ values were utilized for explaining the adsorption isotherm that best fitted. These values were tested graphically to fit into Langmuir, Freundlich, or Temkin isotherms. Among them, Langmuir's isotherm equation (8) fitted the best as seen in Figure $8(a)$. The linear regression coefficient values $\left(R^{2}\right)$ were found to be between 0.9990 and 0.9992 .

The equilibrium constant $K_{(\text {ads })}$ was derived from the graph (Figure $8(\mathrm{~b})$ ) using equation (8). The values of standard free energy of adsorption of inhibitor $\left(\Delta G^{\circ}\right.$ ads $)$, the heat of adsorption $\left(\Delta H^{\circ}\right.$ ads $)$, and entropy of adsorption $\left(\Delta S_{\text {ads }}^{\circ}\right)$ were derived from Figure (8) using equation (9). All these data were tabulated as shown in Table 7.

Inhibitor compounds SDS and SDA under investigation are spontaneously getting adsorbed on alloy surface, and the layer being very stable is indicated by the negative values of standard free energy of adsorption. The standard free energy of adsorption values $<-20 \mathrm{~kJ} \mathrm{~mol}^{-1}$ indicates physisorption, and $>-40 \mathrm{~kJ} \mathrm{~mol}^{-1}$ indicates chemisorption [59]. The calculated experimental values were found between -34 and $-37 \mathrm{~kJ} \mathrm{~mole} \mathrm{e}^{-1}$. Hence, the adsorption of SDS and SDS compounds on AA2024 alloy surface may be attributed to be both physical and chemical where chemisorption was found to be predominating. The positive values of $\Delta H^{\circ}$ ads and $\Delta$ $S_{\text {ads }}^{\circ}$ represent substitutional adsorption. This can be attributed to rise in entropy of solvent and more positive water 


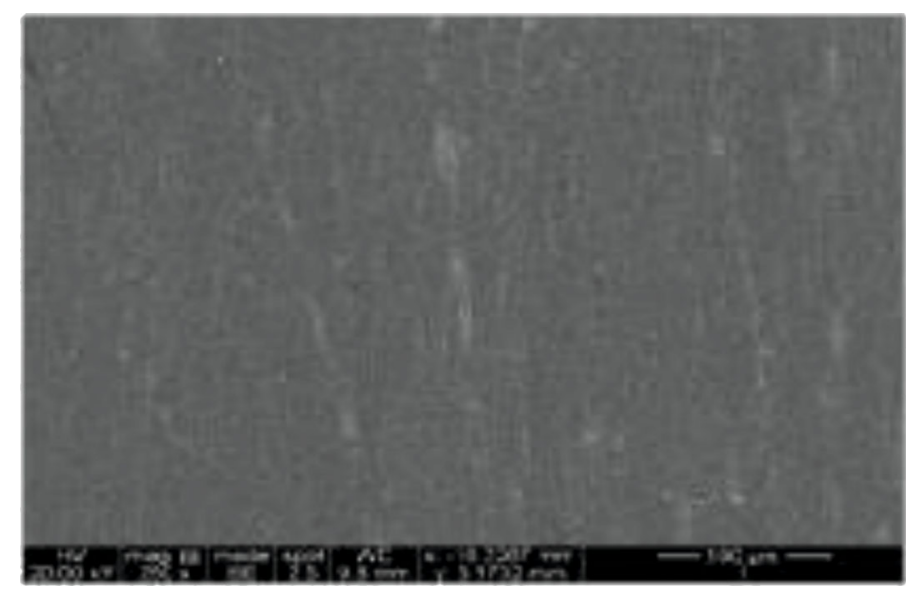

(a)

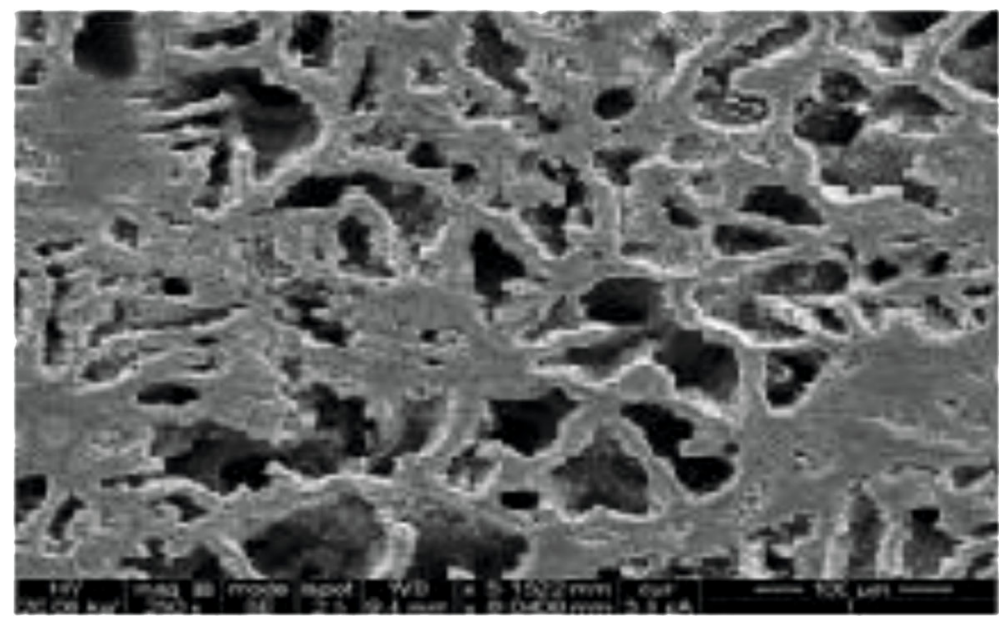

(b)

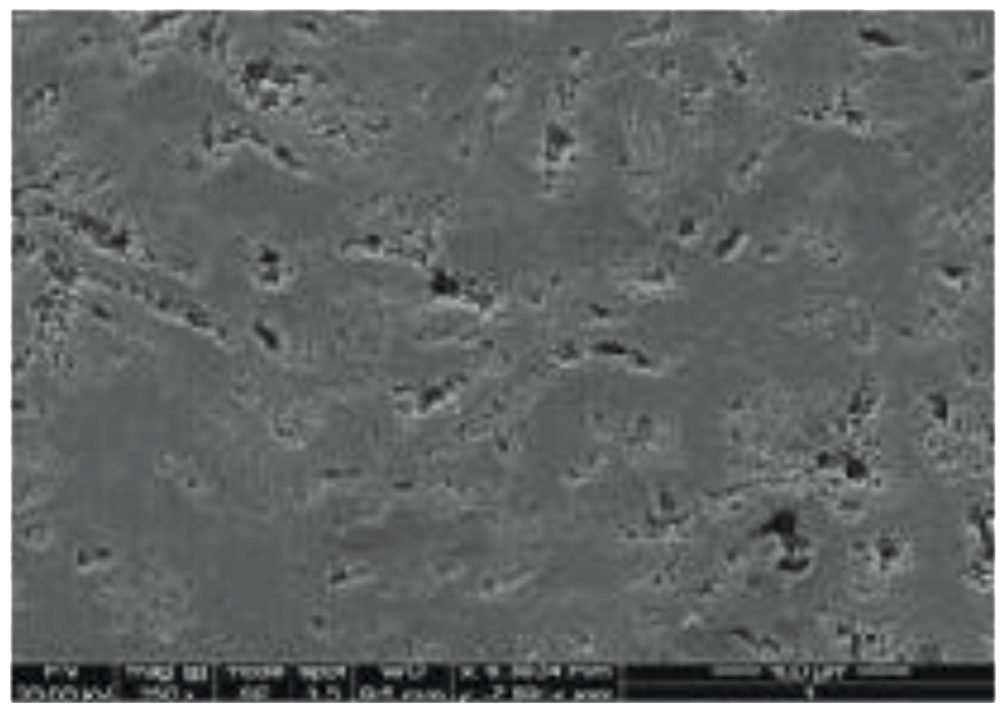

(c)

FIgURe 9: Continued. 


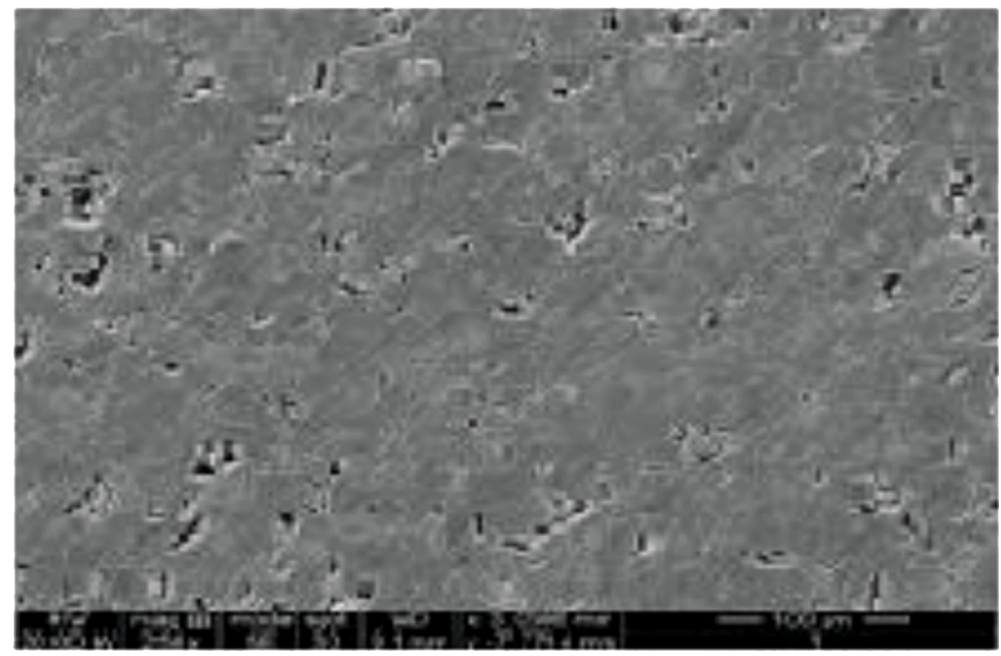

(d)

Figure 9: SEM image of (a) polished AA2024 alloy. (b) Rough surface in the presence of $1 \mathrm{M} \mathrm{HCl}$. (c) Presence of1M HCl and 100 ppm SDS. (d) Presence of $1 \mathrm{MHCl}$ and $100 \mathrm{ppm}$ SDA.

desorption enthalpy. The rise in entropy is the driving force for SDS and SDA molecules getting adsorbed on AA2024 alloy surface.

4.6. Mechanism of Inhibition. In highly acidic solutions, the inhibitor molecules undergo protonation and exist as protonated-positive species [60]. These protonated-positive species adsorb on cathodic sites of alloy surface by electrostatic interaction and resulting in decreased rate for the cathodic reaction. The anions present in the acidic solution and their adsorption on the alloy surface play an important role in the mechanism of inhibition exhibited by inhibitor molecules.

The anions found in the corrosive medium solution assist in the inhibition process by organic compounds by getting adsorbed on alloy surfaces [61]. The corrosive medium used in this investigation is highly acidic, and the alloy surface is positively charged. Because of this, the negative $\mathrm{Cl}^{-}$ions get adsorbed onto the surface of the alloy which makes the alloy surface negatively charged. This results in the physisorption of protonated inhibitor compound molecules which are positively charged interacting with $\mathrm{Cl}^{-}$ions that are adsorbed on alloy surface through electrostatic interaction. The negative charge centers of the inhibitor molecules that contain lone pair of electrons and $\pi$-electrons get involved in an interaction with anodic sites on the alloy surface resulting in their adsorption. The neutral inhibitor molecules occupy the sites on the surface of alloy that is vacant through chemisorption by displacing the water molecules from the alloy surface and sharing of electrons by the heteroatoms like S, N, and O. Inhibitor molecules existing in protonated form and presence of negatively charged centers on the inhibitor molecules are also the reason for inhibitor molecules interacting mutually on the surface of the alloy.

In acidic solution, nitrogen and oxygen atoms from inhibitor molecules may get adsorbed on cathodic sites of
AA2024 alloy surface competing with $\mathrm{H}^{+}$ions. This is a result of organic compounds getting adsorbed via phenolic, amine, and imine groups through the delocalized $\pi$-electrons of the phenolic group, amine and imine nitrogen, and also via electron getting released by $-\mathrm{OH}$ groups. The inhibition efficiency of SDA was found to be higher than that of SDS since it contains more electronegative imine group $-\mathrm{N}=\mathrm{N}-$.

4.7. Scanning Electron Microscopic (SEM) Study. The surface morphology of AA2024 alloy was analyzed using the recorded SEM images of alloy samples polished, exposed for 2 hours in $1 \mathrm{M} \mathrm{HCl}$ in the absence and the presence of $100 \mathrm{ppm}$ SDS and SDA inhibitors. The SEM images of polished AA2024 alloy with smooth surface, with rough surface in presence of $1 \mathrm{M} \mathrm{HCl}$, and less rough surface in presence $1 \mathrm{M} \mathrm{HCl}$ of and $100 \mathrm{ppm}$ of SDS and SDA inhibitors are shown in Figures 9(a)-9(d), respectively.

It is noticed that the alloy surface is damaged to a lesser extent in presence of an inhibitor. The alloy surface is smoother and uniform in the case of SDA than SDS. Thus, it is concluded that both SDA and SDS were proved to exhibit inhibitor mechanism AA2021 alloy surface. In addition, it was also found that SDA protects the AA2024 alloy more effectively than the SDS.

\section{Conclusions}

The inhibition efficiencies obtained by potentiodynamic polarization, electrochemical impedance spectroscopy, and weight loss techniques of Schiff base inhibitors at all concentrations on the AA 2014 alloy in $1 \mathrm{M} \mathrm{HCl}$ are in good agreement.

The inhibition efficiencies of Schiff bases increase in the order: $\mathrm{N}, \mathrm{N}^{\prime}-$ bis( salicylidine) - 4, 4 - 'diaminostilbene $<\mathrm{N}$ , $\mathrm{N}^{\prime}$ - bis( salicylidine $)-4,4^{\prime}-$ diamino azobenzene. 
The increase in inhibition efficiency of Schiff bases is attributed to

(1) The inhibition efficiency of $\mathrm{N}, \mathrm{N}^{\prime}$-bis(salicylidine)$4,4-^{\prime}$ diaminostilbene (SDS) is due to delocalized lone pair of electrons on the electronegative nitrogen atoms in $\mathrm{NH}_{2}, \pi$-electrons of the $-\mathrm{C}=\mathrm{C}$ - group and delocalized $\pi$-electrons of the phenolic group. In addition to the above, groups in Schiff base molecules undergo protonation. The cathodic reaction rate goes down due to protonated species undergoing adsorption over the cathodic sites via electrostatic interaction. Two delocalized $\pi$-electrons of the phenolic groups and electronegative oxygen atoms in the $-\mathrm{OH}$ group also contribute to the inhibition of alloy surfaces through adsorption

(2) The inhibition efficiency of $\mathrm{N}, \mathrm{N}^{\prime}$-bis(salicylidine)4,4-diaminoazobenzene is greater than N, $\mathrm{N}^{\prime}$-bis(salicylidine)-4,4-diaminostilbene that is due to delocalized lone pair of electrons on the electronegative nitrogen atoms in $\mathrm{NH}_{2}$, delocalized $\pi$-electrons of the phenolic group, and delocalized electronegative nitrogen atoms in the imine group $(-\mathrm{N}=\mathrm{N}-)$. In addition to the above, groups in the Schiff base molecule undergo protonation. The cathodic reaction rate goes down due to protonated species undergoing adsorption over the cathodic sites via electrostatic interaction. Two delocalized $\pi$-electrons of the phenolic groups and electronegative oxygen atoms in - $\mathrm{OH}$ group also contribute to the inhibition of alloy surface through adsorption

Finally, it can be concluded that both SDA and SDS inhibitors were proved to be potential corrosion inhibitors for AA2021 alloy.

\section{Data Availability}

The [Excel] data used to support the findings of this study are available from the corresponding author upon request.

\section{Conflicts of Interest}

The authors declare that they have no conflicts of interest.

\section{Authors' Contributions}

The concept and experiments were designed and conducted by Mrs Shobha Bhaskara. The original draft of the manuscript was written by Dr Sanaulla Pathapalya Fakrudeen. Editing and compiling of the final draft were done by Dr Tegene Desalegn and Dr $\mathrm{H}$ C Ananda Murthy. The complete supervision of the work was done by Dr Bheemaraju V. All authors read and approved the final manuscript.

\section{References}

[1] T. Dursun and C. Soutis, "Recent developments in advanced aircraft aluminium alloys," Material Design, vol. 56, pp. 862871, 2014.

[2] X. Zhang, Y. Jiao, Y. Yu et al., "Intergranular corrosion in AA2024-T3 aluminium alloy: the influence of stored energy and prediction," Corrosion Science, vol. 155, pp. 1-12, 2019.

[3] G. S. Chen, M. Gao, and R. P. Wei, "Microconstituent-Induced Pitting Corrosion in Aluminum Alloy 2024-T3," Corrosion, vol. 52, no. 1, pp. 8-15, 1996.

[4] S. V. Lamakaa, M. L. Zheludkevich, K. A. Yasakau, M. F. Montemorb, and M. G. S. Ferreira, "High effective organic corrosion inhibitors for 2024 aluminium alloy," Electrochimica Acta, vol. 52, no. 25, pp. 7231-7247, 2007.

[5] A. N. Khramov, N. N. Voevodin, V. N. Balbyshev, and M. S. Donley, "Hybrid organo-ceramic corrosion protection coatings with encapsulated organic corrosion inhibitors," Thin Solid Films, vol. 447-448, pp. 549-557, 2004.

[6] M. Benabdellah, A. Tounsi, K. F. Khaled, and B. Hammouti, "Thermodynamic, chemical and electrochemical investigations of 2-mercapto benzimidazole as corrosion inhibitor for mild steel in hydrochloric acid solutions," Arabian Journal of Chemistry, vol. 4, pp. 17-24, 2011.

[7] A. C. Balaskas, M. Curioni, and G. E. Thompson, "Effectiveness of 2-mercaptobenzothiazole, 8-hydroxyquinoline and benzotriazole as corrosion inhibitors on AA 2024-T3 assessed by electrochemical methods," Surface Interface Analysis-Wiley Online Library, vol. 47, no. 11, pp. 1029-1039, 2015.

[8] B. G. Prakashaiah, A. Nityananda Shetty, and B. E. Amitharani, "2-(4-(Diethylamino)-2-hydroxybenzyledene) hydrazinecarboamide as corrosion inhibitor on AA2024-T3 aluminium alloy in 0.5 M hydrochloric acid solution," Surface Engineering and Applied Electrochemistry, vol. 54, no. 3, pp. 286-296, 2018.

[9] K. Xhanari and M. Finsgar, "Organic corrosion inhibitors for aluminium and its alloys in chloride and alkaline solutions: A review," Arabian Journal of Chemistry, vol. 12, pp. 46464663, 2019.

[10] A. Khadraoui, A. Khelifa, K. Hachama, and R. Mehdaoui, "Thymus algeriensis extract as a new eco-friendly corrosion inhibitor for 2024 aluminium alloy in $1 \mathrm{M} \mathrm{HCl}$ medium," Journal of Molecular Liquids, vol. 214, pp. 293-297, 2016.

[11] V. Bheemaraju, P. F. Sanaulla, H. B. Lokesh, and H. C. Ananda Murthy, "Electrochemical investigation of corrosion inhibition of AA6063 alloy in 1M hydrochloric acid using Schiff base compounds," IOSR Journal of Applied Chemistry (IOSR-JAC), vol. 2, no. 5, pp. 37-47, 2012.

[12] P. F. Sanaulla, H. C. Ananda Murthy, and V. Bheemaraju, "Corrosion inhibition of AA6061 and AA6063 alloy in hydrochloric acid media by Schiff base compounds," Journal of the Chilean Chemical Society, vol. 57, no. 4, pp. 1364-1370, 2012.

[13] V. Bheemaraju, "Electrochemical behaviour of AA6061 alloy in $1 \mathrm{M}$ hydrochloric acid using Schiff base compounds as corrosion inhibitors," Journal of Materials and Environmental Science, vol. 4, no. 3, pp. 326-337, 2013.

[14] P. F. Sanaulla and V. Bheemaraju, "Inhibitive effect of N,N'bis(salicylidene)-1,2-diaminoethane and $\mathrm{NN}^{\prime}$-bis(3-methoxy salicylidene)-1,2-diaminoethane on the corrosion of AA6061 alloy in hydrochloric acid," Journal of Applicable Chemistry, vol. 2, no. 4, pp. 940-957, 2017.

[15] Y. Zuo, B. Zhou, and Y. Tang, "Inhibition of AA 2024-T3 corrosion in alkaline $\mathrm{NaCl}$ solution by compound sodium 
dodecylbenzenesulfonate and cerium chloride," International Journal of Electrochemical Science, vol. 12, pp. 11137-11149, 2017.

[16] M. Mohammadi, A. Yazdani, F. Mohammadi, and A. Alfantazi, "Corrosion behaviour of 2024 aluminium alloy anodized in sulfuric acid containing inorganic inhibitor," in Light Metals, Part of The Minerals, Metals \& Materials Series book series (MMMS), pp. 509-513, Springer, Cham, 2013.

[17] G. Boisier, N. Portail, and N. Pébère, "Corrosion inhibition of 2024 aluminium alloy by sodium decanoate," Electrochimica Acta, vol. 55, no. 21, pp. 6182-6189, 2010.

[18] B. W. Samuels, K. Sotoudeh, and R. T. Foley, "Inhibition and acceleration of Aluminum corrosion," Corrosion, vol. 37, no. 2, pp. 92-97, 1981.

[19] T. Stimpfling, P. Vialat, H. Hintze-Bruening et al., "Amino acid interleaved layered double hydroxides as promising hybrid materials for AA2024 corrosion inhibition," European Journal for Inorganic Chemistry, vol. 2016, pp. 2006-2016, 2016.

[20] B. Xiang, X. Zuo, Q. Wang, and Z. Wei, "Inhibition of tryptophan on AA 2024 in chloride-containing solutions," Journal of Materials Engineering and Performance, vol. 20, no. 2, pp. 265270, 2017.

[21] B. G. Prakashaiah, D. Vinaya Kumara, A. Anup Pandith, A. Nityananda Shetty, and B. E. Amitha Rani, "Corrosion inhibition of 2024-T3 aluminum alloy in 3.5\% NaCl by thiosemicarbazone derivatives," Corrosion Science, vol. 136, pp. 326338, 2018.

[22] W. Qafsaoui, M. W. Kendig, H. Perrot, and H. Takenouti, "Effect of 1-pyrrolidine dithiocarbamate on the galvanic coupling resistance of intermetallics - aluminium matrix during corrosion of AA 2024-T3 in a dilute $\mathrm{NaCl}$," Corrosion Science, vol. 92, pp. 245-255, 2015.

[23] M. Iannuzzi and G. S. Frankel, "Mechanisms of corrosion inhibition of AA2024-T3 by vanadates," Corrosion Science, vol. 49, no. 5, pp. 2371-2391, 2007.

[24] H. Elgahawi, M. Gobara, and A. Baraka, "Eco-friendly corrosion inhibition of AA2024 in $3.5 \% \mathrm{NaCl}$ using the extract of Linum usitatissimum Seeds," Journal of Bio and Tribo Corrosion, vol. 3, no. 4, pp. 55-67, 2017.

[25] D. Ho, N. Brack, J. Scully, T. Markley, M. Forsyth, and B. Hinton, "Cerium dibutylphosphate as a corrosion inhibitor for AA2024-T3 Aluminum alloys," Journal of the Electrochemical Society, vol. 153, no. 9, pp. B392-B401, 2006.

[26] D. Zhu and W. J. V. Ooij, "Corrosion protection of AA 2024T3 by bis-[3-(triethoxysilyl) propyl]tetrasulfide in neutral sodium chloride solution. Part 1: Corrosion of AA 2024-T3," Corrosion Science, vol. 45, no. 10, pp. 2163-2175, 2013.

[27] E. A. Matter, S. Kozhukharov, M. Machkova, and V. Kozhukharov, "Electrochemical studies on the corrosion inhibition of AA2024 aluminium alloy by rare earth ammonium nitrates in $3.5 \% \mathrm{NaCl}$ solutions," Materials and Corrosion, vol. 64, no. 5, pp. 408-414, 2013.

[28] T. G. Harvey, S. G. Hardin, A. E. Hughes et al., "The effect of inhibitor structure on the corrosion of AA2024 and AA7075," Corrosion Science, vol. 53, no. 6, pp. 2184-2190, 2011.

[29] H. Naeimi and A. Heidarnezhad, "Facile, mild and convenient preparation and characterization of some novel Schiff base ligands from synthetic diamines and salicylaldehyde," Bulletin of Chemical Society of Ethiopia, vol. 29, no. 1, pp. 117-122, 2015.
[30] "Standard Practice for Laboratory Immersion Corrosion Testing of Metal-G31-72-2004".

[31] E. S. Ferreira, C. Giacomelli, F. C. Giacomelli, and A. Spinelli, "Evaluation of the inhibitor effect of L-ascorbic acid on the corrosion of mild steel," Materials Chemistry and Physics, vol. 83, pp. 129-134, 2004.

[32] W. H. Li, Q. He, S. T. Zhang, C. L. Pei, and B. R. Hou, "Some new triazole derivatives as inhibitors for mild steel corrosion in acidic medium," Journal of Applied Electrochemistry, vol. 38, no. 3, pp. 289-295, 2008.

[33] A. Yurt, S. Ulutas, and H. Dal, "Electrochemical and theoretical investigation on the corrosion of aluminium in acidic solution containing some Schiff bases," Applied Surface Science, vol. 253, no. 2, pp. 919-925, 2006.

[34] O. Olivares, N. V. Lihanova, B. Gomez et al., "Electrochemical and XPS studies of decylamides of $\alpha$-amino acids adsorption on carbon steel in acidic environment," Applied Surface Science, vol. 252, no. 8, pp. 2894-2909, 2006.

[35] H. C. Ananda Murthy, "Electroanalytical study on the corrosion behaviour of $\mathrm{TiO} 2$ particulate reinforced $\mathrm{Al} 6061$ composites," Material Science Research India, vol. 12, no. 2, pp. 112-126, 2015.

[36] W. H. Ailor, Engine coolant testing: state of the art, ASTM International, 1980.

[37] M. G. Fontana and N. D. Greene, Corrosion Engineering, McGraw-Hill, New York, 1967.

[38] M. G. Fontana, Corrosion Engineering, McGraw-Hill, New York, Third Edition edition, 1987.

[39] H. C. A. Murthy and S. K. Singh, "Influence of TiC particulate reinforcement on the corrosion behaviour of $\mathrm{Al} 6061$ metal matrix composites," Advanced Materials Letters, vol. 6, no. 7, pp. 633-640, 2015.

[40] F. N. Spellar, Corrosion: Causes and Prevention- an Engineering Problem, Mc Graw Hill, New York, 8 Edition edition, 1935.

[41] H. A. Murthy, V. B. Raju, and C. Shivakumara, "Effect of TiN particulate reinforcement on corrosive behaviour of aluminium 6061 composites in chloride medium," Meddelelser fra Carlsberg laboratoriet, vol. 36, no. 6, pp. 1057-1066, 2013.

[42] M. Pourbiax, Atlas of Electrochemical Equilibria in Aqueous Solutions, NACE International, Houston, TX, 1974.

[43] J. A. V. Butler, "Studies in heterogeneous equilibria. Part II.-The kinetic interpretation of the Nernst theory of electromotive force," Trans. Faraday Soc., vol. 19, no. March, pp. 729-733, 1924.

[44] H. J. W. Lenderink, M. V. D. Linden, and J. H. W. De Wit, "Corrosion of aluminium in acidic and neutral solutions," Electrochimica Acta, vol. 38, no. 14, pp. 1989-1992, 1993.

[45] F. Mansfeld, C. H. Tsai, and H. Shih, Computer Modelling in Corrosion, R. S. Munn, Ed., ASTM, Philadelphia, PA, 1992.

[46] C. H. Hsu and F. Mansfeld, "Technical Note:Concerning the conversion of the constant phase element parameter Y0into a capacitance," Corrosion, vol. 57, no. 9, pp. 747-748, 2001.

[47] T. Erdey-Gruz and M. Z. Volmer, The theory hydrogen overvoltage, Physikal Chemistry, Leipzig, 150 edition, 1930.

[48] C. Wagner and W. Traud, "On the interpretation of corrosion processes through the superposition of electrochemical partial processes and on the potential of mixed electrodes," Journal of Electrochemistry, vol. 44, pp. 391-402, 1983.

[49] S. Haruyama, T. Tsuru, and M. Anan, "Corrosion monitor based on impedance method; construction and its application 
to homogeneous corrosion," Corrosion Engineering, vol. 27, no. 11, pp. 573-579, 1978.

[50] F. Mansfeld, M. W. Kendig, and S. Tsai, "Recording and analysis of AC impedance data for corrosion Studies," Corrosion, vol. 38, no. 11, pp. 570-580, 1982.

[51] K. Hladky, L. M. Callow, and J. L. Dawson, "Corrosion rates from impedance measurements: an introduction," British Corrosion Journal, vol. 15, pp. 21-25, 1980.

[52] F. Bourelier and K. Vagang, Proc. 10th International Congress on Metallic Corrosion, pp. 2813-2900, 1987.

[53] S. Muralidhran, M. A. Quraishi, and S. V. K. Iyer, "The effect of molecular structure on hydrogen permeation and the corrosion inhibition of mild steel in acidic solutions," Corrosion Science, vol. 37, no. 11, pp. 1739-1750, 1995.

[54] G. W. Wrangler, An Introduction to Corrosion and Protection of Metals, Chapman and Hall, London, 1985.

[55] NACE, "National Association of Corrosion EngineersGlossary of Corrosion Terms," Mater. Prot., vol. 4, pp. 7985,1965

[56] D. M. Drazic, Modern Aspects of Electrochemistry, Plenum Press, New York, 1989.

[57] F. Mazza and N. D. Greena, Proc. 2nd Eur. Symp. on Corros, Inhib. Univ. of Ferrara, Ferrara, Italy, 1965.

[58] R. H. Halusler, "Corrosion chemistry," ACS. Symp. Series, vol. 89, p. 262, 1979.

[59] G. W. Poling, "Infrared studies of protective films formed by acetylenic corrosion inhibitors," Journal of Electrochemical Society, vol. 114, no. 12, pp. 1209-1214, 1967.

[60] G. L. Zucchini, F. Zucchi, and G. Trabenelli, 3rd Eur. Symp. on Corros, Inhi, Ferrara, Italy, 1971.

[61] U. R. Evans, Metallic Corrosion, Passivity and Protection, Edward Arnold and Co., London, 1948. 